\title{
A new fossil rorqual (Mammalia, Cetacea, Balaenopteridae) from the Early Pliocene of the North Sea, with a review of the rorqual species described by Owen and Van Beneden
}

\author{
Mark BOSSELAERS \\ Koninklijk Zeeuwsch Genootschap der Wetenschappen, \\ 4331 JE Middelburg (The Netherlands) \\ and Royal Belgian Institute of Natural Sciences, \\ 1000 Brussels (Belgium) \\ mark.bosselaers@telenet.be \\ Klaas POST \\ Natuurhistorisch Museum Rotterdam, \\ 3015 AA Rotterdam (The Netherlands) \\ klaaspost@fishcon.nl
}

KEY WORDS

Mammalia, Cetacea,

Mysticeti,

Balaenopteridae,

Early Pliocene,

North Sea,

anatomy,

phylogeny,

Van Beneden,

Owen,

review,

new genus,

new species.
Bosselaers M. \& Post K. 2010. - A new fossil rorqual (Mammalia, Cetacea, Balaenopteridae) from the Early Pliocene of the North Sea, with a review of the rorqual species described by Owen and Van Beneden. Geodiversitas 32 (2): 331-363.

\section{ABSTRACT}

A fossil rorqual - Diunatans luctoretemergo n. gen., n. sp. - is described based on two specimens from the early Pliocene of The Netherlands and is compared to all previously described rorquals. The morphology of the new species, especially that of the elements of the petrotympanic complex, is described in detail. Main discriminating characters are: very short nasal; mediolaterally wide pterygoid fossa; large, robust and prominent occipital condyle; mediolaterally wide squamosal body lateral to the supraoccipital; dorsal bulge on squamosal; tympanic bulla very large compared to zygomatic width; wide tympanic bulla (L/W ratio: 1.24) with the sigmoid process perpendicular to the long axis of the bulla; rounded and bulbous pars cochlearis (L/W ratio: 1.23-1.26); long, slender and curved stapes; massive and square basioccipital process; wide basioccipital. A phylogenetic analysis has been undertaken based on a recently published matrix. In the consensus tree the new taxon has a basal position with respect to the Balaenoptera + Megaptera clade and constitutes therefore a stembalaenopterid. Taxonomic controversies surrounding nominal rorqual species described during the 19th century from North Sea strata are addressed. Our analysis of the type material of the species Balaenoptera borealina, B. musculoides, B. rostratella, Megaptera affinis, Megapteropsis robusta and Plesiocetus goropii lead us to declare them nomina dubia. 


\author{
MOTS CLÉS \\ Mammalia, \\ Cetacea, \\ Mysticeti, \\ Balaenopteridae, \\ Pliocène inférieur, \\ Mer du Nord, \\ anatomie, \\ phylogénie, \\ Van Beneden, \\ Owen, \\ révision, \\ genre nouveau, \\ espèce nouvelle.
}

\section{RÉSUMÉ}

Un nouveau rorqual fossile (Mammalia, Cetacea, Balaenopteridae) du Pliocène inférieur de la Mer du Nord et révision des espèces de rorquals décrites par Owen et Van Beneden.

Un nouveau rorqual fossile - Diunatans luctoretemergo n. gen., n. sp. - est décrit sur la base de deux spécimens du Pliocène inférieur des Pays-Bas et comparé à tous les rorquals préalablement décrits. La morphologie du crâne de cette nouvelle espèce, particulièrement les éléments du complexe pétro-tympanique, est décrite en détail. Les principaux caractères diagnostiques sont: nasal très court; fosse ptérygoïde large médio-latéralement; condyle occipital grand, robuste et proéminent; squamosal large latéralement au supraoccipital; protubérance dorsale sur le squamosal; bulle tympanique très grande par rapport à la largeur zygomatique; bulle tympanique large (rapport entre longueur et largeur: 1,24) avec le processus sigmoïde perpendiculaire à l'axe longitudinal de la bulle; pars cochlearis sub-circulaire et bulbeuse (rapport entre longueur et largeur: 1,23-1,26); étrier long, gracile, et recourbé; processus du basioccipital massif et carré; basioccipital large. Une analyse phylogénétique a été entreprise sur base d'une matrice récemment publiée. Dans l'arbre de consensus le nouveau taxon occupe une position plus basale que le clade Balaenoptera + Megaptera, et constitue ainsi un stem-balaenoptéridé. Les controverses taxonomiques concernant les espèces de rorquals décrites durant le XIXe siècle, principalement par Van Beneden, à partir de spécimens des strates de la Mer du Nord sont abordées. L'analyse du matériel type des espèces fossiles Balaenoptera borealina, B. musculoides, B. rostratella, Megaptera affinis, Megapteropsis robusta et Plesiocetus goropii nous mène à déclarer celles-ci nomina dubia.

\section{INTRODUCTION}

The work of Owen (1844) and the famous and brilliantly illustrated volumes of Van Beneden (1882) established the North Sea as a rich source of Miocene and Pliocene fossil mysticetes. Unfortunately these publications have caused serious nomenclatural puzzles and taxonomic controversies, hampering scientific work until the present day (True 1912; Winge 1921; Kellogg 1922; Slijper 1936; Abel 1938; De Smet 1978; Deméré 1986; Steeman 2004, 2007; Bisconti 2007). Deméré et al. (2005) summarized most of these problems and concluded that only drastic action might solve them. Their conclusion that the taxonomic status of the nominal fossil mysticetes from the
North Sea has to be clarified is justified because controversies have left important fossils unstudied for decades.

We therefore propose a revision of the mysticete specimens described in the 19th century from North Sea sediments. All nominal taxa based on non-diagnostic cranial fragments, single petrotympanic elements and/or postcrania should be re-discussed and the validity of these taxa must depend on undisputed characters of basicranium, vertex and petrotympanic complex.

Herein we also describe, for the first time since the 19th Century, a new fossil rorqual, Diunatans luctoretemergo n. gen., n. sp., from the North Sea and compare it to all published fossil rorquals (Balaenopteridae). 


\section{MATERIAL AND METHODS}

\section{ABBREVIATIONS \\ Institutions \\ IRSNB Institut royal des Sciences naturelles de Belgique, Brussels, Belgium; \\ KZGW Koninklijk Zeeuwsch Genootschap der Weten- schappen, Middelburg, The Netherlands; \\ NHG Natuurhistorische collectie van het Zeeuws Genootschap der Wetenschappen, Middel- burg, The Netherlands; \\ RMNH Naturalis, Nationaal Natuurhistorisch Mu- seum, Leiden, The Netherlands.}

\section{Anatomy}

Skull:

Alis alisphenoid;

Bo basioccipital;

Bop basioccipital process;

ch choanae;

eam external auditory meatus;

ExOcc exoccipital;

fm foramen magnum;

fpo foramen pseudovale;

Fr frontal;

jn jugular notch;

Mx maxilla;

$\mathrm{Na}$ nasal;

occ occipital condyle;

onc optic nerve conduct;

$\mathrm{Pa} \quad$ parietal;

Pal palatine;

pgp postglenoid process of squamosal;

PMx premaxilla;

$\mathrm{Pt} \quad$ pterygoid;

Pts pterygoid sinus;

sBoPt basioccipital-pterygoid suture;

Socc supraoccipital;

sop supraorbital process of frontal;

sPaFr parietal-frontal suture;

$\mathrm{Sq} \quad$ squamosal;

Sqcr squamosal crest;

Sqcl squamosal cleft;

Sqpdb posterodorsal bulge of squamosal;

sSqPt squamosal-pterygoid suture;

stf sternomastoid fossa;

Vo vomer;

zyp zygomatic process of squamosal.

Petrotympanic

Tympanic:

al anterior lip;

ca conical apophysis;

dl dorsal lobe;

$\begin{array}{ll}\text { dmr } & \text { dorsomedian ridge; } \\ \text { et } & \text { notch for eustachian tube; } \\ \text { iv } & \text { involucrum; } \\ \text { map } & \text { mallear pedicle; } \\ \text { medk } & \text { medial keel; } \\ \text { ppp } & \text { pedicle of posterior process of petrotympanic; } \\ \text { sg } & \text { sigmoid process; } \\ \text { ty } & \text { tympanic. }\end{array}$

Petrosal:

ap anterior process;

aplp lateral projection of anterior process;

app (br) pedicle of anterior process (broken);

co cochlea;

ct crista transversa;

ctpp caudal tympanic process of petrosal;

elf endolymphatic foramen;

es endocranial sulcus;

fc fenestra cochlearis;

fhm fossa for head of malleus;

fs sulcus for the facial nerve;

fsm fossa for stapedial muscle;

fslm fossa for stylomastoid;

fv fenestra vestibuli;

gtt groove for tensor tympani;

IAM internal auditory meatus;

lfap lateral foramen of anterior process;

pc pars cochlearis;

plf perilymphatic foramen;

pp posterior process of periotic;

prg promontorial groove;

pyd pyramidal process;

VII facial nerve canal;

VII-cran endocranial facial foramen;

VII-lat lateroposterior facial foramen.

Malleus:

ah articular head;

aas anterior articular surface;

ma manubrium;

mas median articular surface;

ped (br) pedicle of malleus (broken).

Incus:

afm anterior facet for malleus;

$\mathrm{cb} \quad$ crus breve (medial tubercle);

cl crus longum (stapedial process);

fst facet for stapes;

lfm lateral facet for malleus.

Stapes:

fai facet for articulation with the incus;

sf stapedial foramen;

sfp stapedial foot plate;

st stapes. 


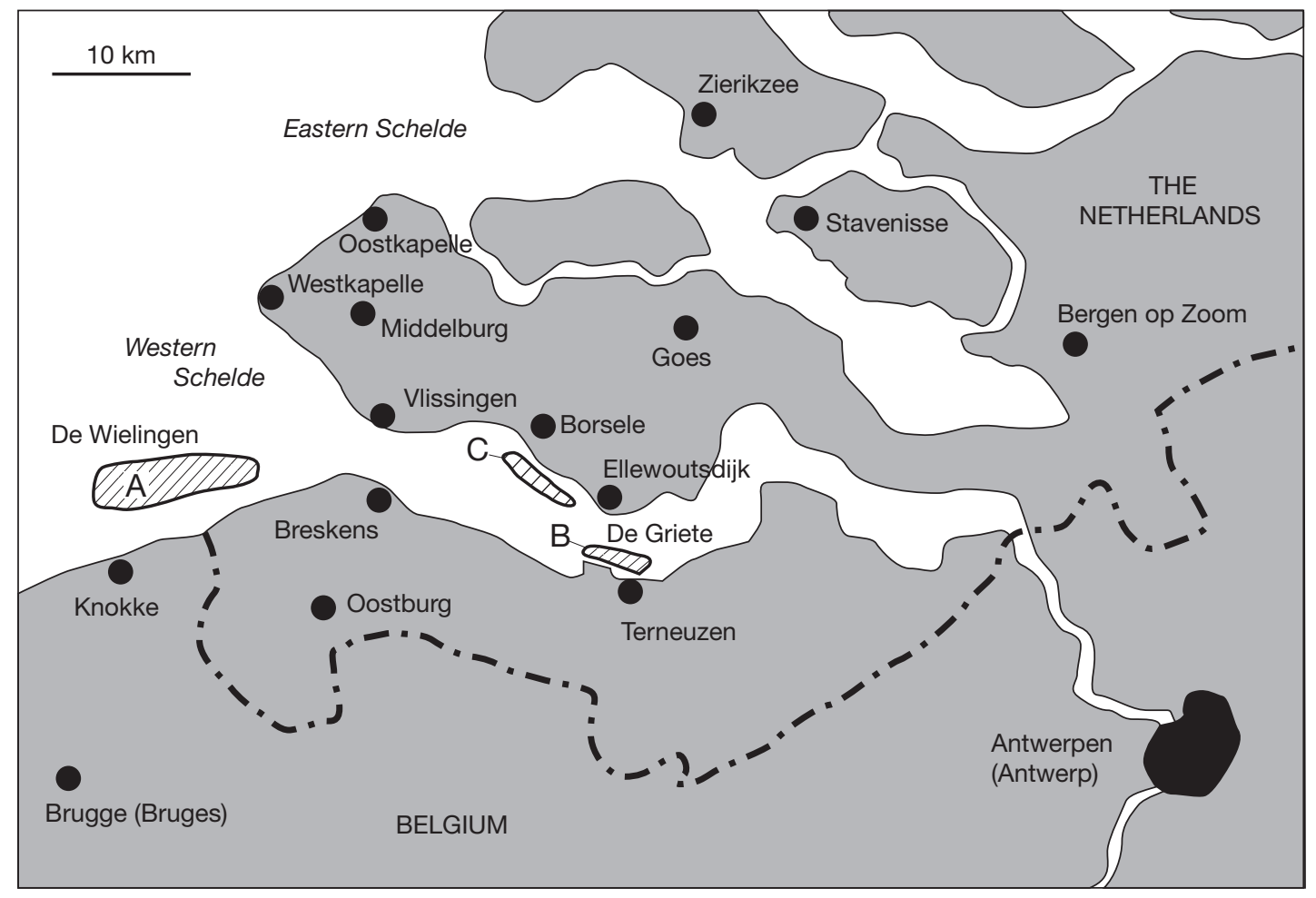

FIG. 1. - The estuary of the Schelde river at the Belgian-Dutch border. Late Miocene-mid Pliocene cetacean fossils have been trawled from three locations in the 1930s: A, De Wielingen, in front of Knokke; B, De Griete and De Braakman near Terneuzen; C, along the riverbank near Borsele and Ellewoudsdijk.

Post-cranial skeleton:

Atlas atlas;

Axis axis;

Cerv cervical vertebra;

Thyr Thyrohyale.

Two fossil skulls were rediscovered in the collections of the KZGW. The holotype specimen (NHG 22279) is a fairly complete neurocranium, with petrotympanics and 4 cervical vertebrae, preserved in the original matrix. The paratype specimen (NHG 22347) is a posterior left half of a neurocranium, with a periotic.

Rorquals are, in this study, considered to be members of the family Balaenopteridae Gray, 1864 (including stem-Balaenopteridae and crown-Balaenopteridae [Balaenopterinae Flower, 1865 and Megapterinae Flower, 1865]).

Specimens of all extant rorquals except $B$. bonaerensis Burmeister, 1867 and B. omurai Wada, Oishi \& Yamada, 2003, and original material of all fossil taxa named by Owen and Van Beneden, as well as fossil B. siberi Pilleri \& Pilleri, 1989, B. cortesii (Fisher, 1829) and Cetotheriophanes capellinii (Brandt, 1873) were studied.

A revision of all the Balaenopteridae described by Owen and Van Beneden in the 19th century is performed (see Appendix 1). New IRSNB catalogue numbers are used and their reference to old register numbers (as used by Van Beneden) is presented in Appendix 2.

Taxonomic terminology follows Gardner \& Hayssen (2004) and Bouetel \& de Muizon (2006). Tympanic terminology follows Oishi \& Hasegawa (1994a: fig. 3) (see also Bouetel \& de Muizon [2006]).

For measurements see Appendix 3 and Figure 14.

For list of molluscs, recovered from the matrix surrounding the type specimen of $D$. luctoretemergo n. gen., n. sp. see Appendix 4. 


\section{SYSTEMATICS}

\author{
Order CETACEA Brisson, 1762 \\ Suborder AUTOCETA Haeckel, 1866 \\ Infraorder MYSTICETI Flower, 1864 \\ Family BALAENOPTERIDAE Gray, 1864
}

\section{Genus Diunatans n. gen.}

TYPE SPECIES. - Diunatans luctoretemergo n. sp.

ETymology. - Diunatans: "diu" = long time (and hence long distance-) and "natans" (> natare) $=$ swimming (swimmer).

DiAGNOSIs. - Diunatans n. gen. is a small sized rorqual, roughly of the size of extant $B$. acutorostrata Lacépède, 1804, characterised by: very short nasal; mediolaterally wide pterygoid fossa; large, robust and prominent occipital condyle; mediolaterally wide squamosal body lateral to the supraoccipital; dorsal bulge on squamosal; tympanic bulla very large compared to zygomatic width; wide, globose tympanic bulla (L/W ratio: 1.24$)$ with sigmoid process perpendicular to long axis; rounded and bulbous pars cochlearis (L/W ratio: 1.23-1.26); very long, slender and curved stapes; massive and square basioccipital process; wide basioccipital.

\section{Diunatans luctoretemergo n. sp.}

HoLOTYPE. - NHG 22279: neurocranium with nasals, ascending fragments of maxilla and premaxilla, damaged frontals (the lateral part of the sop is missing), parietals, occipitals, squamosals, petrotympanic complexes, fragment of hyoid and four cervical vertebrae. Most of the rostral elements anterior to the vertex, and the dentaries, are missing (Figs 2-4; 7-9; 11; 12).

PARATYPE. - NHG 22347: damaged neurocranium with left occipital condyle, left half of basicranium and basisphenoid, left pterygoid, left periotic (the tympanic bulla is missing), left squamosal, left half of supraoccipital, and the posterior process of palatine (overlapping the pterygoid) (Figs 5; 6; 10).

ETYMOLOGY. - After the motto "Luctor et Emergo" of the Dutch province Zeeland where holotype and paratype specimens were collected and rediscovered, thus symbolising the rise of the specimens above the sea surface and - perhaps even more spectacular - their survival after being forgotten for 70 years on dusty museum shelves.

Diagnosis. - As for genus.
Horizon And AGE. - Zanclean, Kattendijk Formation, Kattendijk Sand Member (?), Early Pliocene.

Type Locality. - Scheldt river estuary, The Netherlands (Fig. 1).

DifFERENTIAL DIAGNOSIS. - Diunatans luctoretemergo n. gen., n. sp. is a member of the family Balaenopteridae because it shows: 1) abruptly depressed supraorbital process of the frontal; 2) lateral border of the supraoccipital overhanging the temporal fossa; 3) prominent squamosal crest; 4) parietals overlapping the posteromedial corner of the supraorbital process of the frontal; 5) ascending process of the premaxilla reaching the nasal; 6) maxilla, premaxilla and nasal reaching frontal and/or supraoccipital in a rectilinear or almost rectilinear line; 7) tympanic bulla with a weak, single and simple main ridge; and 8) anterior process of periotic triangular and ventromedial-dorsolaterally compressed.

Diunatans luctoretemergo n. gen., n. sp. differs from: - all extant Balaenopterinae, extant Megaptera novaeanglia (Borowski, 1781) and the nominal fossil rorquals B. cortesii; B. cuvierii (Fisher, 1829); Megaptera hubachi Dathe, 1983 and Megaptera miocaena Kellogg, 1922, in the morphology of the squamosal, the large, robust and prominent occipital condyle, the size of the tympanic bulla (relatively the largest of the family) and the orientation of its sigmoid process, and in the prominent promontorial groove of the periotic;

- Balaenoptera siberi, in the morphology of the squamosal, the large, robust and prominent occipital condyle, in the size of the tympanic bulla and the direction of its sigmoid process, and in the rounded pars cochlearis (pers. obs.). This species is poorly described. It shows basal features and does not belong in the genus Balaenoptera (Bisconti pers. comm.; pers. obs.);

- fossil B. cortesii var. portisi Sacco, 1890; B. ryani (Hanna \& McLellan, 1924); Cetotheriophanes capellinii; Parabalaenoptera baulinensis Zeigler, Chan \& Barnes, 1997, by the short rectangular nasal;

- fossil B. davidsonii (Cope, 1872) because this species is based on a few mandibular characters only and therefore - in fact - may not be considered a valid taxon.

The fossil Megapteropsis robusta Van Beneden, 1872 (= Megaptera affinis Van Beneden, 1880); B. borealina Van Beneden, 1880; B. definata (Owen, 1844); B. emarginata (Owen, 1844); B. gibbosa (Owen, 1844); B. rostratella Van Beneden, 1880; B. sibbaldina Van Beneden, 1880; Plesiocetus goropii Van Beneden, 1859 (= B. musculoides Van Beneden, 1882) are considered nomina dubia (see Appendix 1) and are therefore not compared to D. luctoretemergo n. gen., n. sp.

Diunatans luctoretemergo n. gen., n. sp. is not compared to $B$. gastaldi (Strobel, 1875) because this is an eschrichtiid (Bisconti 2008); nor to Eobalaenoptera harrisoni Dooley, Fraser \& Luo, 2004 because this a mysticete of 
uncertain taxonomic affinity (Deméré et al. 2005). Additionaly the nominal fossil rorquals $B$. cortesii, $B$. cortesii var. portisi and B. cuvierii are probably not balaenopterids and are awaiting taxonomic revision (Deméré et al. 2005; Bisconti in litt.)

\section{DESCRIPTION}

The description is based on NHG 22279 and NHG 22347 . Both small crania have a zygomatic width of c. $750 \mathrm{~mm}$. They belong to full grown individuals because all cranial sutures are fused, the posterior process of the periotic is firmly attached to the cranium, and NHG 22279 shows cervical vertebral epyphyses firmly fused to the vertebral bodies.

\section{Skull}

Maxilla. About $115 \mathrm{~mm}$ of the ascending process of the maxilla is preserved. In dorsal view it is broad posteriorly $(42 \mathrm{~mm})$, ventrodorsally flattened and interdigitated with the frontal on the vertex (as in Balaenoptera). In anterior view, the cross-section is comma-shaped, with a medial thickening. In lateral view the slope of the ascending process of the maxilla and premaxilla is $c .15^{\circ}$ to the horizontal plane (Figs 2; 4).

Premaxilla. About $109 \mathrm{~mm}$ of the ascending process of the premaxilla is preserved. It is wedged between the nasal and the ascending process of the maxilla. Posteriorly it overlays the frontal, dorsally it is relatively wide and in anterior cross-section it is comma-shaped (Figs 2; 4).

Nasal. The nasal is similar to the nasal of extant rorquals B. physalus (Linnaeus, 1758), B. musculus (Linnaeus, 1758) and Megaptera novaeangliae, but differs from that of $B$. acutorostrata, B. omurai, B. edeni Anderson, 1878 and B. borealis Lesson, 1828 (M. Bisconti pers. comm.; pers. obs.), the nasals of which lack the dorso-medial crest and show a convex anterior side. The nasal is roughly trapezoidal in dorsal view, slightly narrowing posteriorly and the nasals are wedged between the ascending processes of the premaxillae. Posteriorly they contact the frontals on the vertex. The dorsal surface of the naso-frontal suture is damaged; however it seems that the naso-frontal contact was probably not thoroughly interdigitated. Anteriorly the nasals are (slightly) concave (Figs 2; 3).
Frontal. The frontal is exposed over the entire width of the vertex (anteroposterior $\mathrm{L}=20 \mathrm{~mm}$ laterodorsally on the vertex) and protrudes dorsomedially (which results in a chevron-like shape in dorsal view). In lateral view, it is exposed dorsally over at least $120 \mathrm{~mm}$. It is overlapped anterodorsally by the ascending process of the maxilla, and by the parietal posteriorly. The lateral extensions of both supraorbital processes are missing; only their posteromedial bases are preserved. The parietal overlaps the posteromedial corner of the supraorbital process. The base of the supraorbital process of the frontal is abruptly depressed. On the anteromedial wall of the temporal fossa, the fronto-parietal (coronal) suture runs at an angle of $45^{\circ}$ in the direction of the anterior end of the optic nerve conduct. It continues dorsal to the base of the supraorbital process, and contacts the alisphenoid posteroventral to the posterior base of the optic nerve conduct (Figs 2; 4).

Parietal. Both parietals are completely preserved. The parietal is not exposed on the vertex, except for a 5 $\mathrm{mm}$ wide triangular lateral wing. The anterior process of the parietal is vertical to slightly concave in anteroposterior section, and reaches $c .50 \mathrm{~mm}$ anterior to the posterior end of the ascending process of the maxilla and c. $40 \mathrm{~mm}$ to that of the premaxilla. From the posterodorsal side of the alisphenoid, the parietalsquamosal suture starts. It extends posterodorsally upwards, to join the posterior side of the lateral border of the supraoccipital shield (lambdoid crest), just behind the posterior side of the optic nerve conduct (similar to sutures noted in $B$. musculus and $M$. novaeangliae). The parietal is pressed against the lateral border of the supraoccipital, up to the fronto-parietal suture at the vertex. The dorsolateral parietal border strongly overhangs the temporal fossa (Figs 2; 4).

Vomer. The vomer is visible anteriorly as a V-shaped gutter-like bone, lateroposteriorly covered by (fragments of) the palatine. In ventral view, the vomer is exposed between the palatines (however because of damage) and posterior to the palatines, where it is part of the medioventral wall of the choanae extending posteriorly till the anterior side of the bop. Posteriorly it covers the basicranium and posterolaterally the pterygoids (Figs 3; 4). 


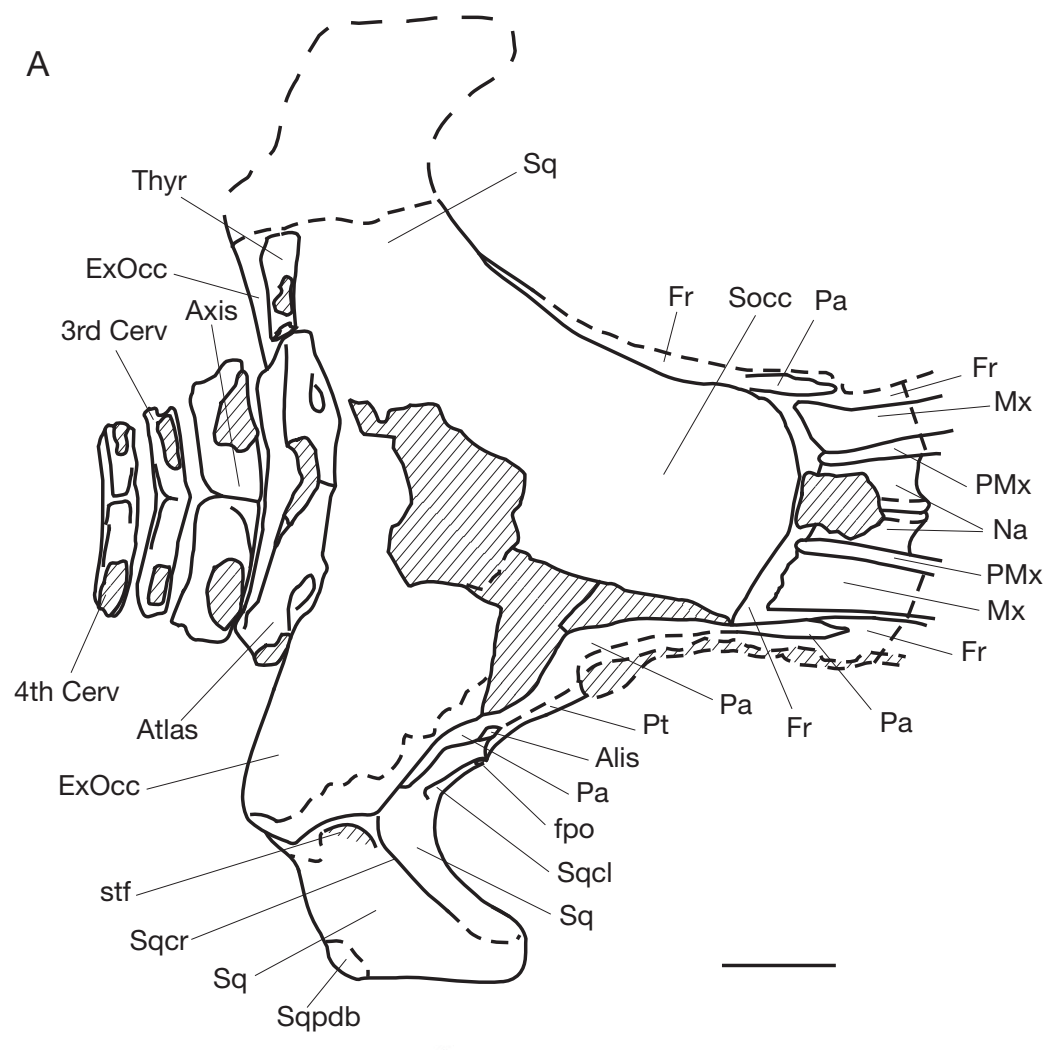

B

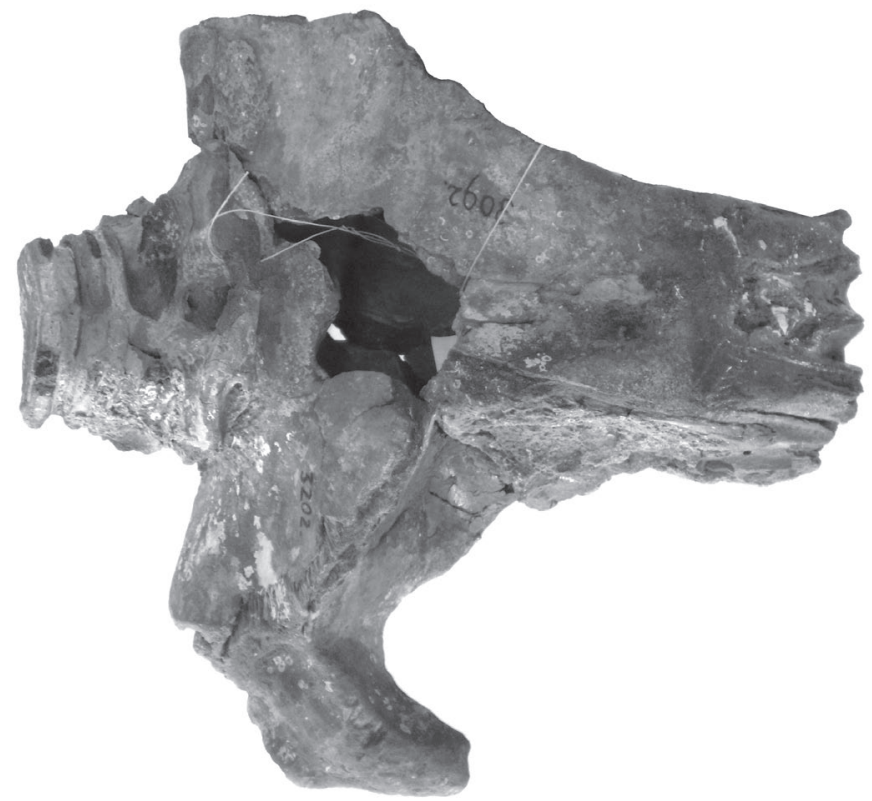

FIG. 2. - Diunatans luctoretemergo n. gen., n. sp., holotype NHG 22279-a, b: A, dorsal view, line drawing; B, dorsal view, photograph. Abbreviations: see p. 333, 334. Scale bar: $10 \mathrm{~cm}$. 
A

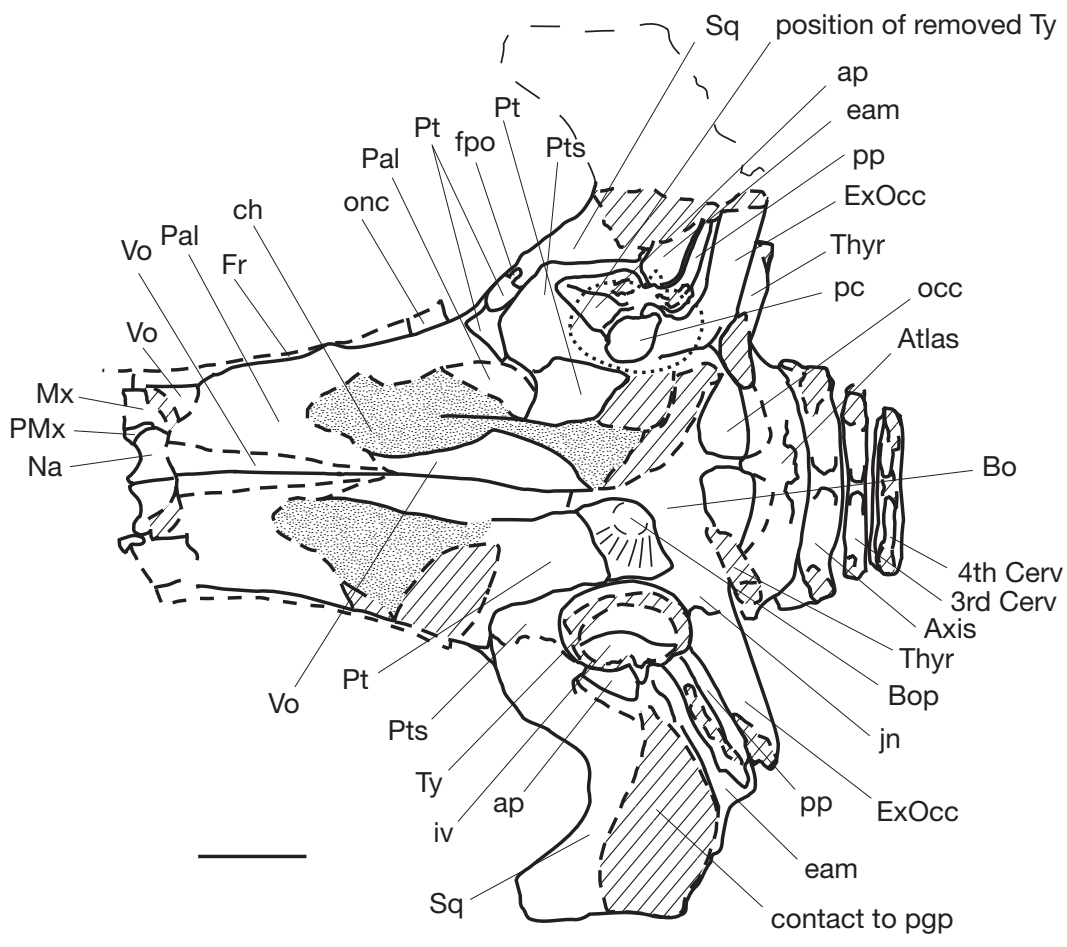

B

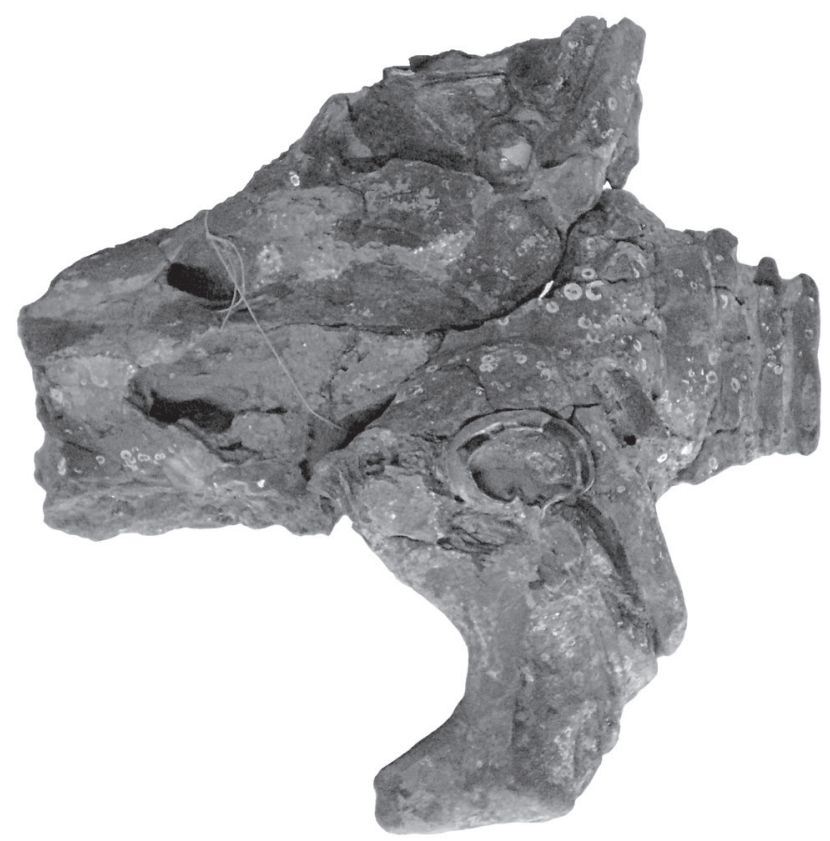

FIG. 3. - Diunatans luctoretemergo n. gen., n. sp., holotype NHG 22279-a, b: A, ventral view, line drawing; B, ventral view, photograph. Abbreviations: see p. 333,334 . Scale bar: $10 \mathrm{~cm}$. 

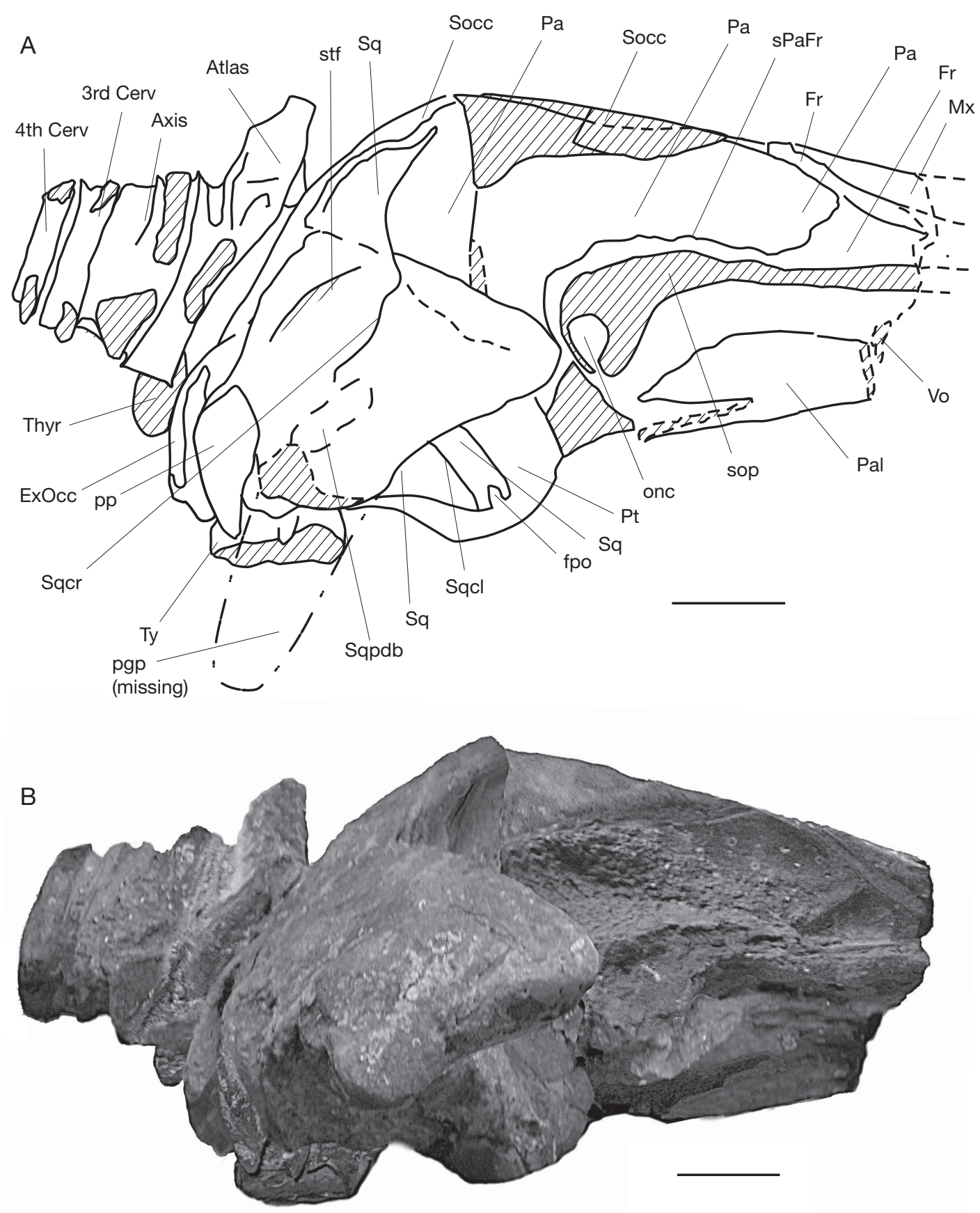

FIG. 4. - Diunatans luctoretemergo n. gen., n. sp., holotype NHG 22279-a, b: A, right lateral view, line drawing; B, right lateral view, photograph. Abbreviations: see p. 333, 334. Scale bars: $10 \mathrm{~cm}$. 
Palatine. In ventral view, the palatine extends posterolaterally almost to the level of the dorsolateral edges. Posterodorsally the palatine contacts the anteroventral wall of the optic nerve conduct of the frontal (Figs 3; 4).

Pterygoid. A small part of the pterygoid contributes to the anteromedial edge of the foramen pseudovale. Most of the wall of the pterygoid sinus is made up by the pterygoid; only its posterior part is formed by the basioccipital. Medioventrally the medial wing of the pterygoid sinus extends as far posterior as to the centre of the pars cochlearis, where it contacts the descending process of the basioccipital. The pterygoid fossa is wide compared to the zygomatic width of the skull $(c .110 \mathrm{~mm}$ in transverse diameter). Laterally the pterygoid is overlaid by the squamosal. In anterolateral view, the pterygoid is ventrodorsally elevated and forms part of the ventral wall of the optic nerve conduct (as in B. acutorostrata) (Figs 3; 4; 6).

Alisphenoid. The alisphenoid shows a triangular form. It is narrow, and positioned a few centimetres posteroventral to the posterior base of the optic nerve conduct (Fig. 2).

Squamosal. In lateral view, the squamosal is anteroposteriorely short and not pointed, wide in posterior and anterior views, and is distinctly separated from the supraoccipital. It is large and especially strongly developed towards the lateral border of the supraoccipital shield. The posterodorsal side of the squamosal shows a bulge. The zygomatic process is slender. It is tapering anteriorly; the most anterior part is missing. The zygomatic process seems to diverge (slightly) from the skull axis, but due to damage, its orientation is not clear. The mediodorsal edge of the zygomatic process possesses a sharp sigmoid crest that merges posteriorly with the lambdoid crest. The dorsal edge of the zygomatic process is downwards sloping (c. $20^{\circ}$ to the horizontal plane). The postglenoid process is thick, rounded ventrally and oriented posteroventrally at an angle of $c .100^{\circ}$ to the horizontal plane. It tapers medially, becomes blade-like, and is transversely oriented. The articular surface for the mandibular condyle is concave and narrow. The postglenoid fossa (external auditory meatus) is moderately wide anteroposteriorly, with a wide, spoon-shaped depression medially. The postglenoid fossa is not high but quite wide. The squamosal cleft runs parallel to the parietal-squamosal suture. It is long and slender, with a pointed apex located far posteriorly. In dorsal view the squamosal cleft is completely visible (contrary to the condition in B. acutorostrata) and similar to the condition noted in $M$. novaeangliae. The foramen pseudovale is mainly formed by the squamosal, and only the medial anteroventral part is covered by the pterygoid. The anteroventral squamosal-pterygoid suture is strongly concave. The squamosal-parietal suture is medially straight. The posterior wall of the temporal fossa is medially convex and bulges into the temporal fossa. The somewhat roughly surfaced sternomastoid fossa is a shallow depression, which is ventromedially restricted by a weak crest (Figs 2-7).

Supraoccipital. The sub-triangular supraoccipital shield shows a truncated, rectilinear apex; it is strongly concave medially and lacks a medial crest. In dorsal view the lateral border of the supraoccipital is concave and strongly overhangs the temporal fossa (Figs 2; 4; 5; 6C; 7).

Basioccipital. The basioccipital is wide mediolaterally and anteroposteriorly short. Anteroventrally the basioccipital is covered by the vomer. The basioccipital descending process is strong, mediolaterally wide and anteroposteriorly short, as in B. musculus (Figs 3; 5-7).

Exoccipital. The occipital condyles are massive, robust and much more protruding than the rather weak and rounded condyles of the extant Balaenopterinae but - to some extent - more similar to the condyles of $M$. novaeangliae. The well-developed occipital condyle is protruding strongly and extends about as far posteriorly as the exoccipital (in lateral view the condyles are clearly visible, while in all extant rorquals the condyles are partly or completely hidden behind the lateral side of the exoccipital and the occipital). The exoccipital is strong and wide and is oriented posteromedially (Figs 2-7). 


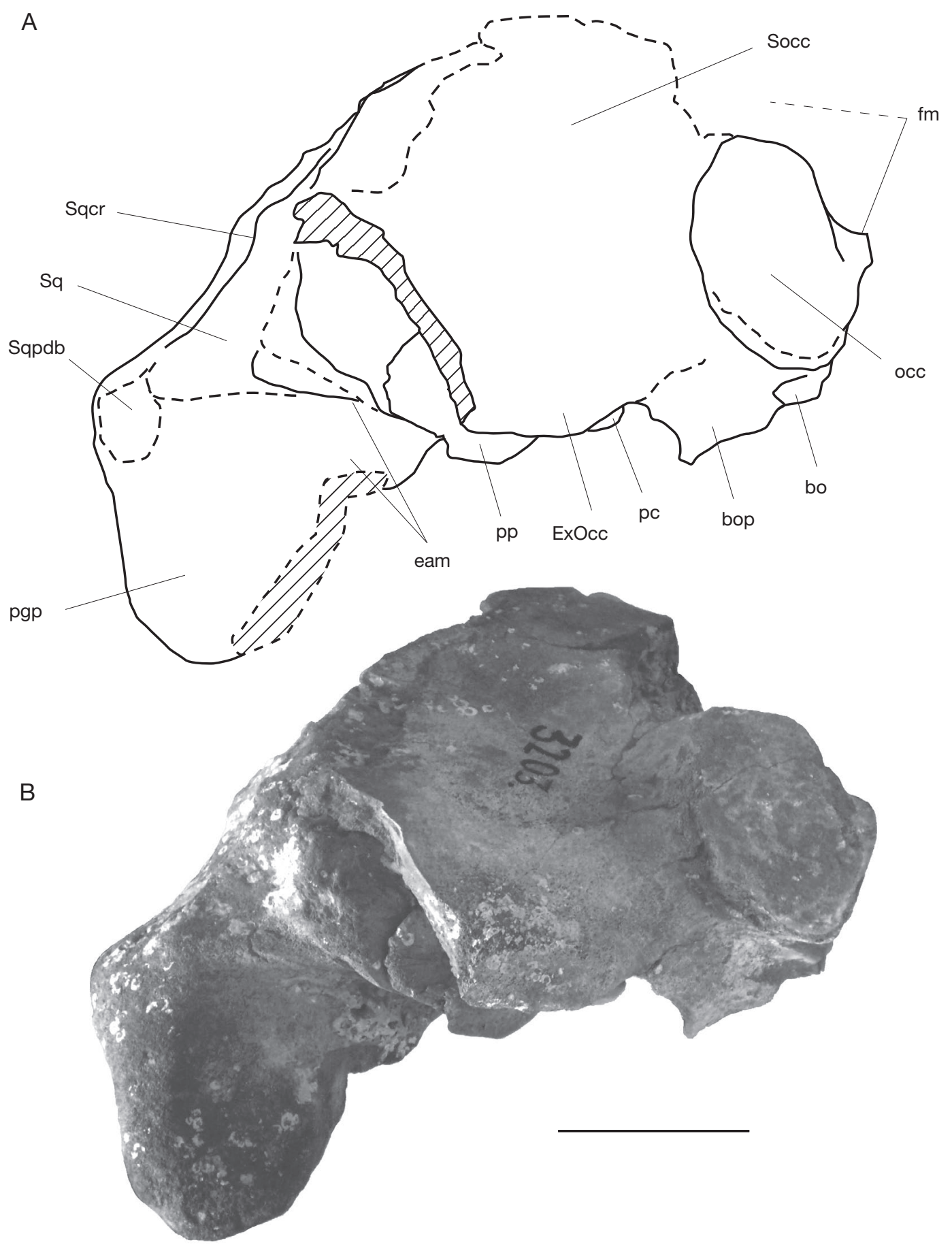

FIG. 5. - Diunatans luctoretemergo n. gen., n. sp., paratype NHG 22347-a: A, posterior view, line drawing; B, posterior view, photograph. Abbreviations: see p. 333, 334. Scale bar: $10 \mathrm{~cm}$. 


\section{Petrotympanic}

Tympanic bulla. After the removal of the left tympanic of the holotype (NHG 22279), the ventral face of the tympanic has been prepared, leaving the maleus and the incus nicely exposed. The greatest mediolateral width is at the level of the sigmoid process, while the greatest length runs parallel to the axis of the cranium. Anteriorly the lip is flattened and smooth. The anterior opening of the Eustachian tube is wide mediolaterally and much wider than in extant rorquals. The anterior half of the involucrum is depressed. It has a few rather weak transverse striae in this region; otherwise the surface is smooth. Anterolaterally, lateral to the Eustachian opening, the involucrum is mediolaterally wide. The involucrum is posteriorly wider, where it is also dorsoventrally flattened (as in all Balaenopteridae) and has a weak dorsal lobe. The dorsomedial ridge is weak. The medial keel is weak and broad. The ventral lobes are not preserved. The sigmoid process is roughly perpendicular to the long axis of the tympanic, whereas it is inclined $17^{\circ}$ to this axis in extant Balaenopteridae. The sigmoid process is well developed and is limited anteriorly by a wide sulcus. The conical apophysis is separated from the sigmoid process by a wide sub-triangular sulcus. The malleus is fused to the anterior side of the sigmoid process. The posterior pedicle of the tympanic is oriented anterolaterally-posteromedially. It is relatively short, wide, strong and located far posteriorly. The bulla is the largest known bulla of the family (relative to the zygomatic width of the cranium) and is wide compared to its length (length/width ratio: 1.24 ) (Figs 3; 4; 7-9).

Periotic. The dorsolateral, dorsal and the dorsomedial (endocranial) side of the periotic of the holotype is still embedded in sediment and is not available for study. Descriptions of these views are therefore based on the paratype (NHG 22347). The left periotic of the paratype was removed from the skull, but the posterior process remains in situ.

On the holotype the anterior process of the periotic, in ventromedial view, is big and almost equilaterally triangular. It is almost twice as long as the anteroposterior length of the pars cochlearis. The anterior process is thick, ventromedially-dorsolaterally flattened and rounded at its ventrolateral and mediodorsal edges, similar to the anterior process of B. physalus, but shorter, wider and more ventromedially-dorsolaterally flattened. Both the ventrolateral and the mediodorsal sides of the anterior process are straight to slightly convex and smooth. The anterior half of the anterior process is covered by the squamosal when viewed ventromedially. In ventromedial view, the pars cochlearis contacts the anterior process over a very short distance only $(20 \mathrm{~mm})$. This is due to the short pars cochlearis and the fact that the endocranial facial sulcus is not roofed medially. The transverse elongation of the pars cochlearis is strongly restricted, and the roof of the medial expansion of the endocranial facial sulcus is apparently not yet fully ossified. In ventromedial view the pars cochlearis is almost circular and strongly bulbous. Such a bulbous pars cochlearis is not yet encountered in fossil and extant Balaenopteridae. Only extant $\mathrm{Meg}$ aptera seem to show a similar (but weaker) feature. The pars cochlearis in Balaenopteridae is usually much more elongate, rather than sub-circular and globose. The transverse elongation of the pars cochlearis is limited in D. luctoretemergo n. gen., n. sp. (L/W ratio: 1.26 [holotype] to 1.23 [paratype]). The caudal tympanic process is strongly developed, obtuse, rounded and tube-shaped, Posteromedially it expands into a shelf. The anteroposterior distance between the anterior process and the posterior process of the periotic is large, and filled by the medially spoon-shaped and anteroposteriorly wide postglenoid fossa. Anteriorly, and separating the pars cochlearis from the anterior process, is a weak groove for the tensor tympani muscle, as still present in some extant rorqual specimens. Halfway on the ventrolateral side (ventrolateral ridge sensu Geisler \& Luo 1996) is a large and deep foramen. The suprameatal fossa (squamosal fossa sensu Geisler \& Luo 1996) is weak at the edges. Posteriorly, on the ventrolateral ridge is a rather prominent subtriangular ventrolateral projection (aplp sensu Geisler \& Luo 1996). Medial to the ventrolateral projection is the anteroposteriorly oriented anterior pedicle of the periotic. This pedicle is triangular and short. Posterior to this pedicle, lateral to the pars cochlearis is a small shallow and hardly visible fossa for the head of the malleus. 


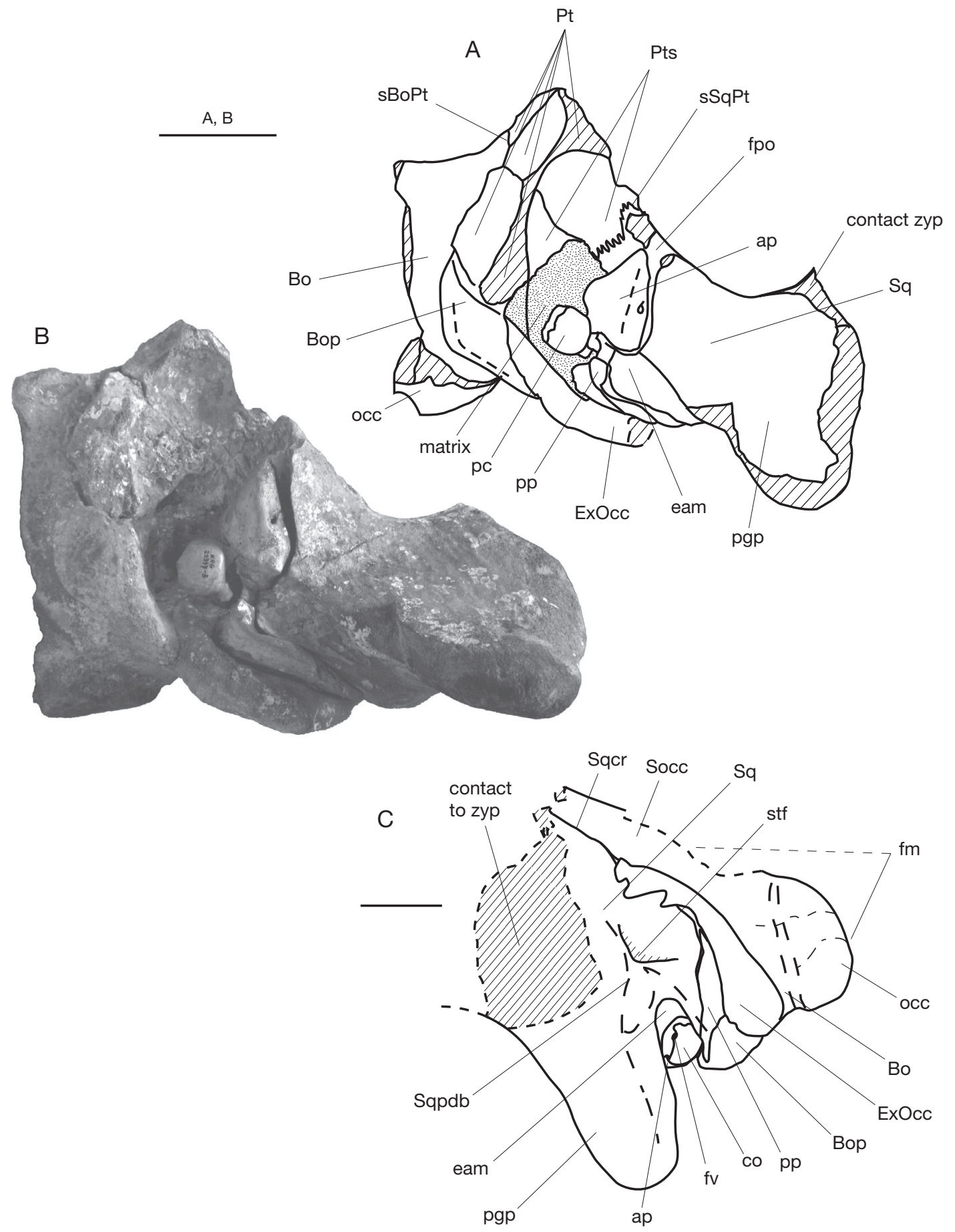

FIG. 6. - Diunatans luctoretemergo n. gen., n. sp., paratype NHG 22347-a, b: A, ventral view, line drawing; B, ventral view, photograph; C, left lateral view, line drawing. Abbreviations: see p. 333, 334. Scale bars: A, B, $10 \mathrm{~cm} ; \mathrm{C}, 5 \mathrm{~cm}$. 


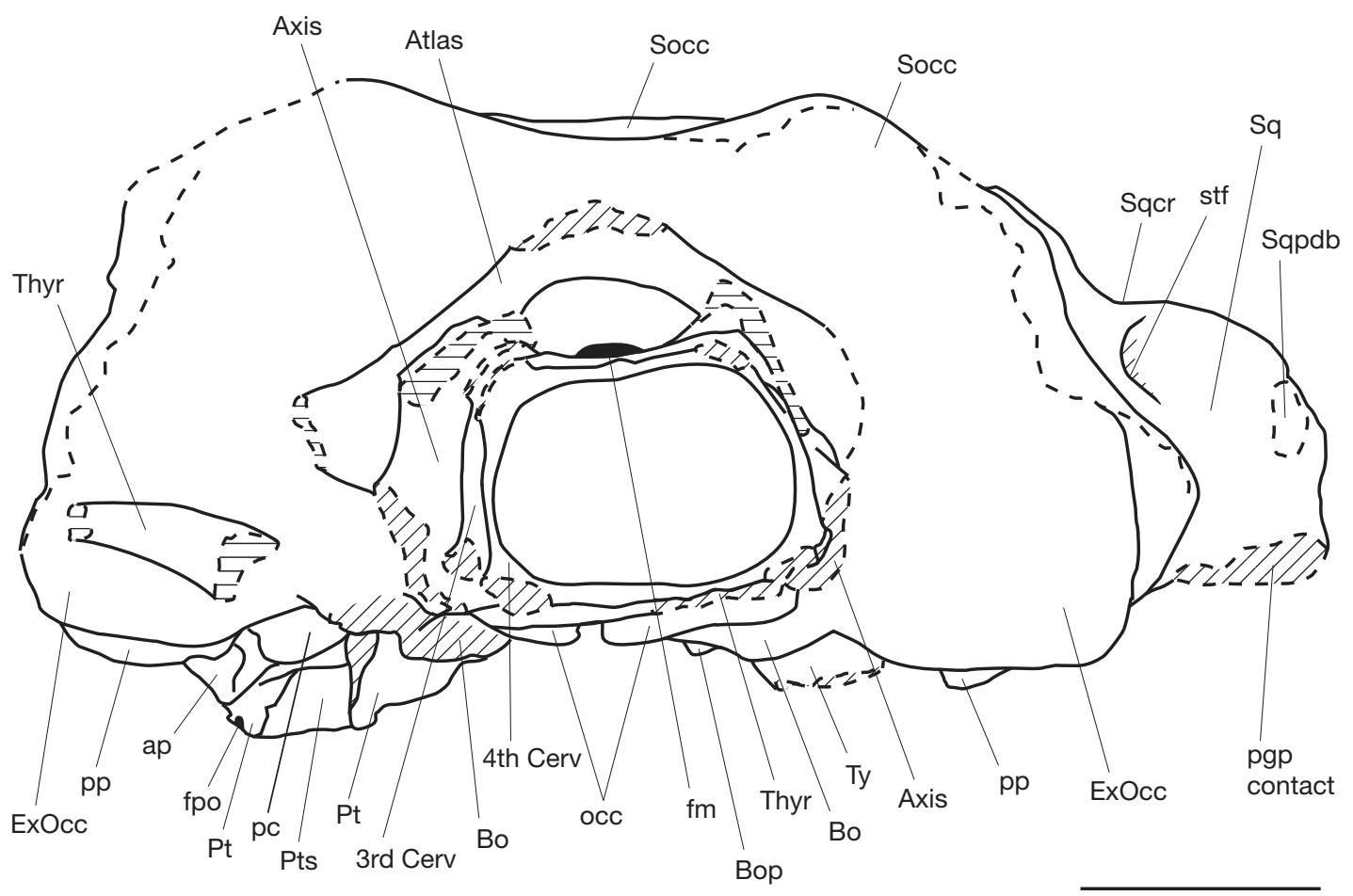

FIG. 7. - Diunatans luctoretemergo n. gen., n. sp., holotype NHG 22279-a, b, posterior view of cranium and vertebrae, line drawing. Abbreviations: see p. 333, 334. Scale bar: $10 \mathrm{~cm}$.

Lateroposterior to the mallear fossa is a deep and wide depression, therefore the periotic lacks a fossa incudis. The incus makes contact only to a narrow mediolaterally oriented crest, just posterior to the mallear fossa. Posterior to this depression is the rather slender, flattened crista petrosa: the base of the posterior process of the periotic. Medial to the crista petrosa is the stapedial muscle fossa. It is deep wide and well defined dorsally. Dorsomedial to the lateral facial sulcus is the stylomastoid fossa. It is also deep, short, and well separated from the stapedial muscle and facial nerve fossae by a thin transverse septum. The fenestra cochlearis is large (diameter $>6 \mathrm{~mm}$ ) and subcircular. The lateroposterior opening of the facial nerve canal is circular and narrow (diameter $c$. $2 \mathrm{~mm}$ ). The posterior process of the petrosal is massive and is firmly attached to the cranium. It is fairly short mediolaterally and anteroposteriorly flattened. Ventrodorsally it is high. The posterior process is at a right angle to the axis of the anterior process.
On the periotic of the paratype, the central area of the dorsolateral side is still covered by a thin layer of sediment and the surface of the bone is smooth at the ventrolateral and mediodorsal border, but probably slightly more rugose at the central area, where the sediment still partly covers the bone. In mediodorsal view, the internal acoustic meatus is sub-circular to oval and is isolated anteriorly from the facial nerve by a thick, robust $(14 \mathrm{~mm})$ crista transversa, and posteriorly from the perilymphatic foramen by the pyramidal process. The posterior wall of the perilymphatic foramen is not ossified. The endolymphatic foramen, just ventral to the posterior side of the internal acoustic meatus, is damaged. The endocranial facial foramen (VII-cran) is either damaged, or positioned very laterally. It is very small and circular $(3 \mathrm{~mm})$. The facial nerve canal continues over the mediodorsal side of the crista transversa, towards the acoustic meatus, to the extent that the endocranial foramen for the 
facial nerve and the internal acoustic meatus are interconnected by a deep, long and narrow sulcus, running over the crista transversa in anteroposterior direction. Ventral to the internal acoustic meatus is a prominent promontorial groove, similar to the structure we observed in some of the periotics of more archaic Balaenopteridae from the Antwerp Lower Pliocene Kattendijk Sands (Bisconti et al. unpubl. data) and from the Lee Creek Mine, North Carolina, USA (pers. obs.). This structure is absent in extant rorquals (Figs 3-8; 10; 11).

Malleus. The description is based on the left malleus of NHG 22279 (holotype). The malleus, incus and stapes were preserved in articulation. The pedicle of the malleus is fused to the anterior edge of the sigmoid process of the bulla. It is robust and bears two parallel columns separated by a deep groove. On its ventral side, the head bears two semi-circular articular facets for the incus. They are at an angle of $c .90^{\circ}$. The dorsal facet is approximately twice as large as the ventral one. This facet is long compared to that of $B$. acutorostrata, but similar in size to that of $B$. physalus and $M$. novaeangliae and therefore long compared to the skull size. Both facets are slightly convex (Figs 8; 11; 12).

Incus. The incus is sub-triangular in medial view. It is $13 \mathrm{~mm}$ long and tapers from $8.5 \mathrm{~mm}$ anteriorly to $2.7 \mathrm{~mm}$ posteriorly. It has an obtuse crus breve. The anterior contact surface to the malleus is big: $8 \times 8.5 \mathrm{~mm}$ (Figs $8 ; 11 ; 12$ ).

Stapes. The stapes is very long and slender (L: $9.5 \mathrm{~mm})$ and very slightly curved, as in $M$. novaeangliae. It has a diameter of $1.7 \mathrm{~mm}$ in the middle, widening to $3.2 \mathrm{~mm}$ posterolaterally (Figs $8 ; 11 ; 12$ ).

\section{Post-cranial skeleton}

Thyrohyal. On the left posterior side of the supraoccipital a $c .101 \mathrm{~mm}$ long and rounded fragment of a hyoid is connected by matrix. Most probably this is a part of the thyrohyal. Its thickest part (48 mm diameter) is located towards the midline of the cranium. On the right side a $80 \mathrm{~mm}$ bone fragment sticks to the ventral side of the atlas. This could be a part of the right thyrohyal (Figs 2-4; 7).

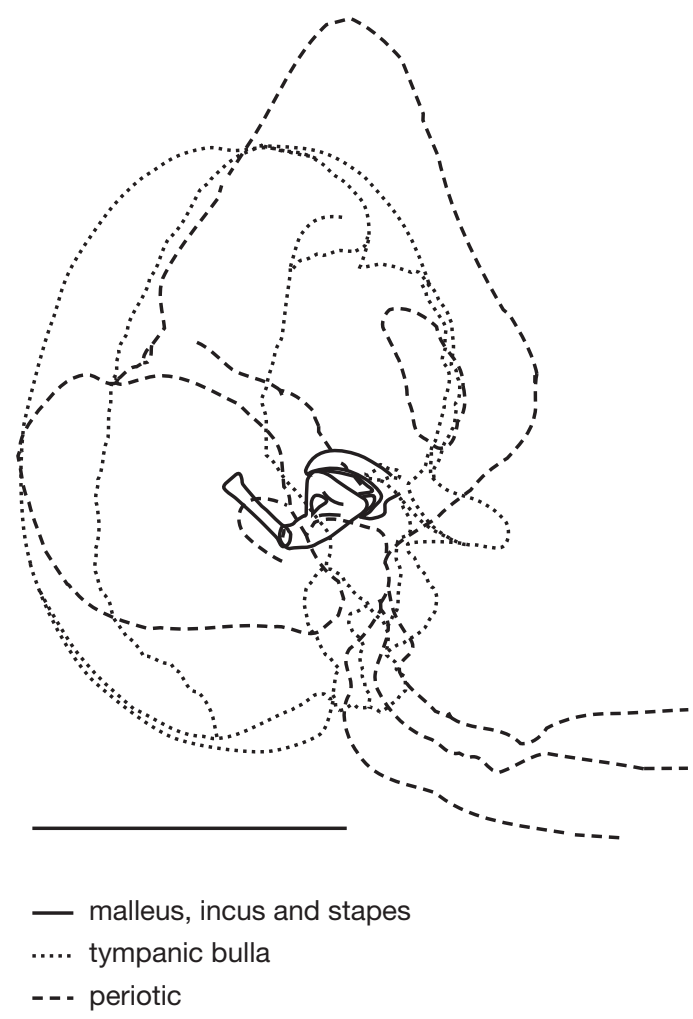

FIG. 8. - Diunatans luctoretemergo n. gen, n. sp., holotype NHG 22279-a, d, e, n, left petrotympanic, ventral view, schematic drawing of the different components. Scale bar: $5 \mathrm{~cm}$.

Cervical vertebrae. Four articulated cervical vertebrae are preserved. The atlas is well preserved and is $250 \mathrm{~mm}$ wide. Its thickest part is located on the centre of the vertebral body $(45 \mathrm{~mm})$; more lateral the thickness gradually reduces to about $35 \mathrm{~mm}$. The neurapophysis is low and carries long, fairly slender and pointed transverse processes. The ventral surface of the vertebral body is almost horizontal. The condylar facets are not visible because the four cervical vertebrae are still attached to the cranium by sediment. The strong curvature visible at some uncovered parts, and the strong curvature of the occipital condyle of the paratype (NHG 22347), hint to a strongly arched surface. The vertebral body of the axis, C3 and C4 are 150, 145 and $130 \mathrm{~mm}$ wide respectively, with their largest thickness at the centre (28, 23 and $19 \mathrm{~mm}$, measured ventrally). They all show a prominent and sharp medial keel on the 
A

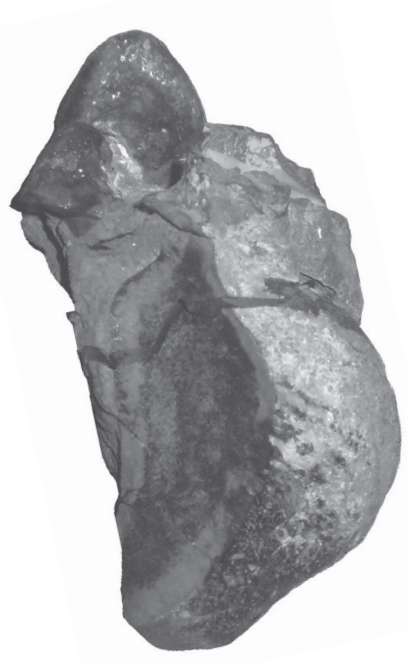

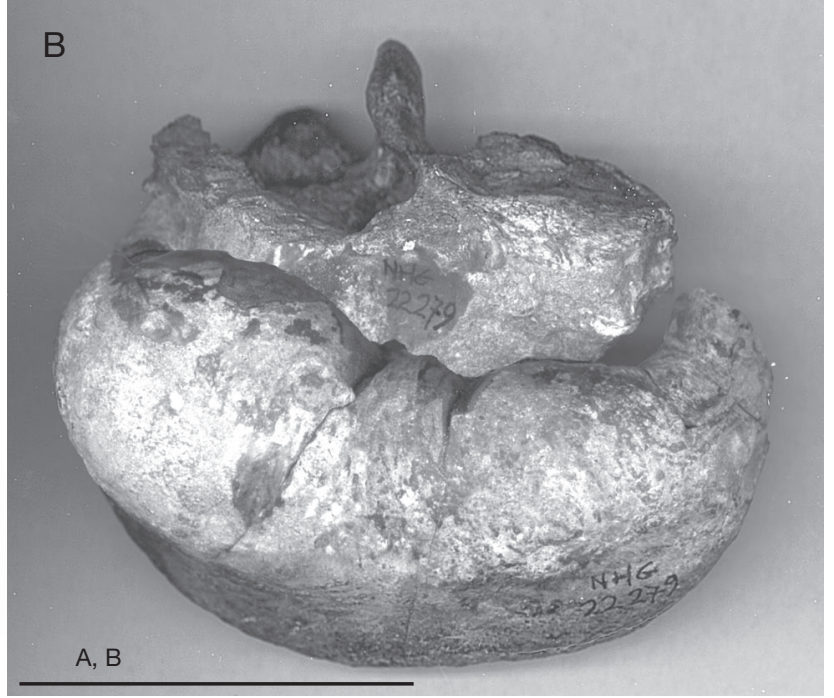

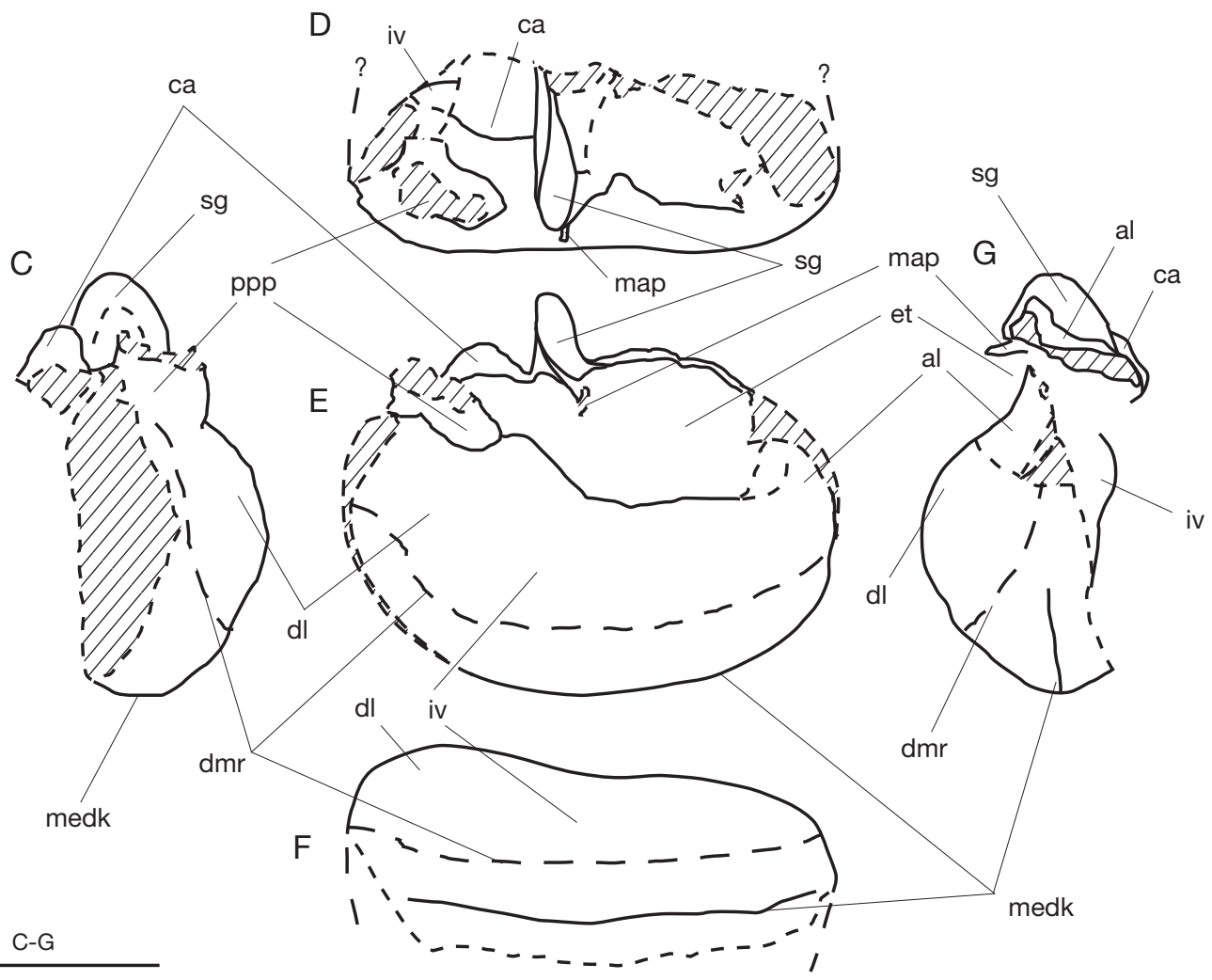

FIG. 9. - Diunatans luctoretemergo n. gen., n sp., holotype NHG 22279-n, left tympanic: A, posterior view, photograph; B, dorsal view, photograph; C, posterior view, line drawing; D, lateral view, line drawing; E, dorsal view, line drawing; F, medial view, line drawing; G, anterior view, line drawing. Abbreviations: see p. 333, 334. Scale bars: $5 \mathrm{~cm}$. 
A

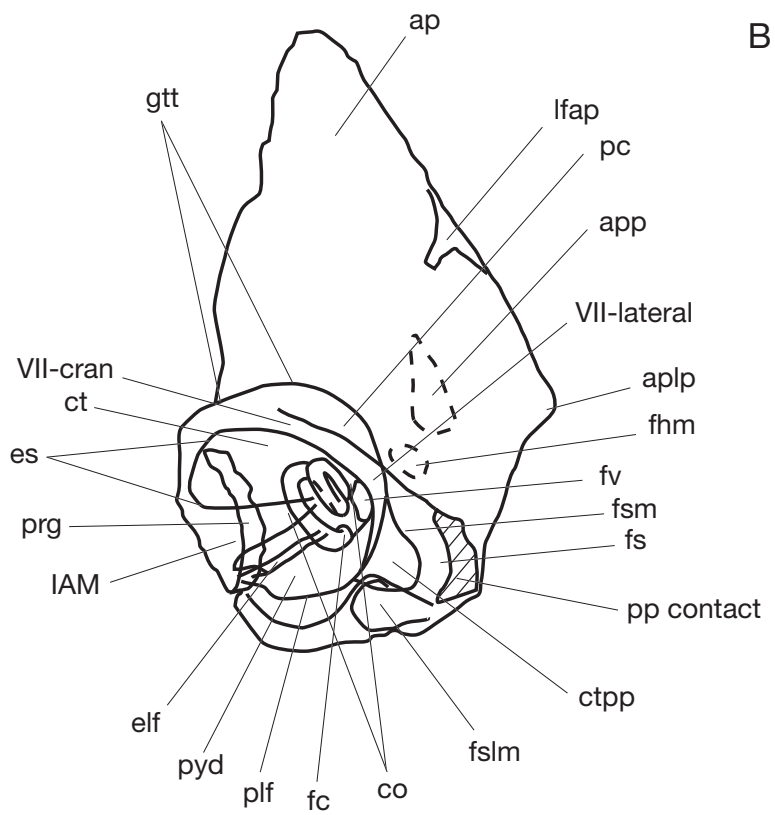

B

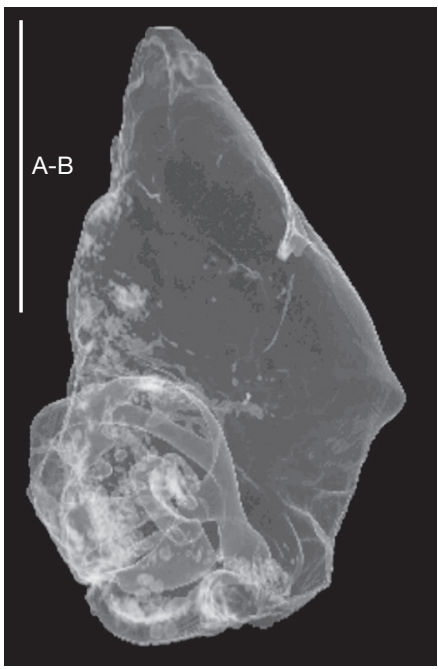

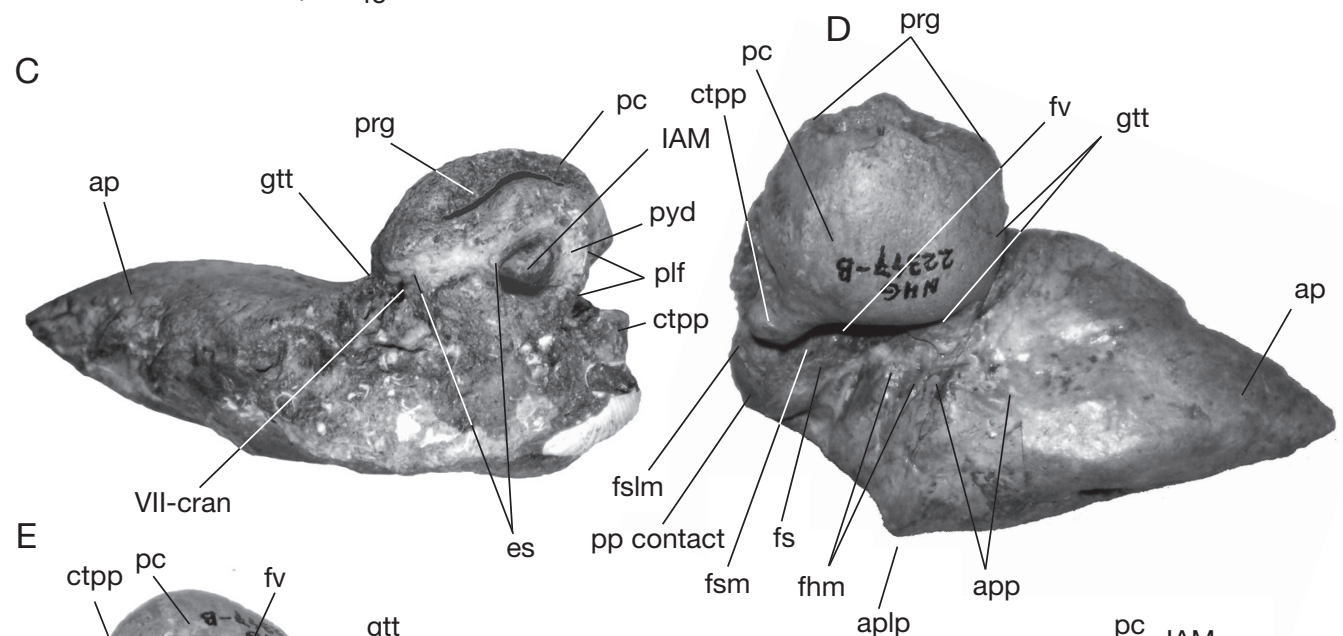
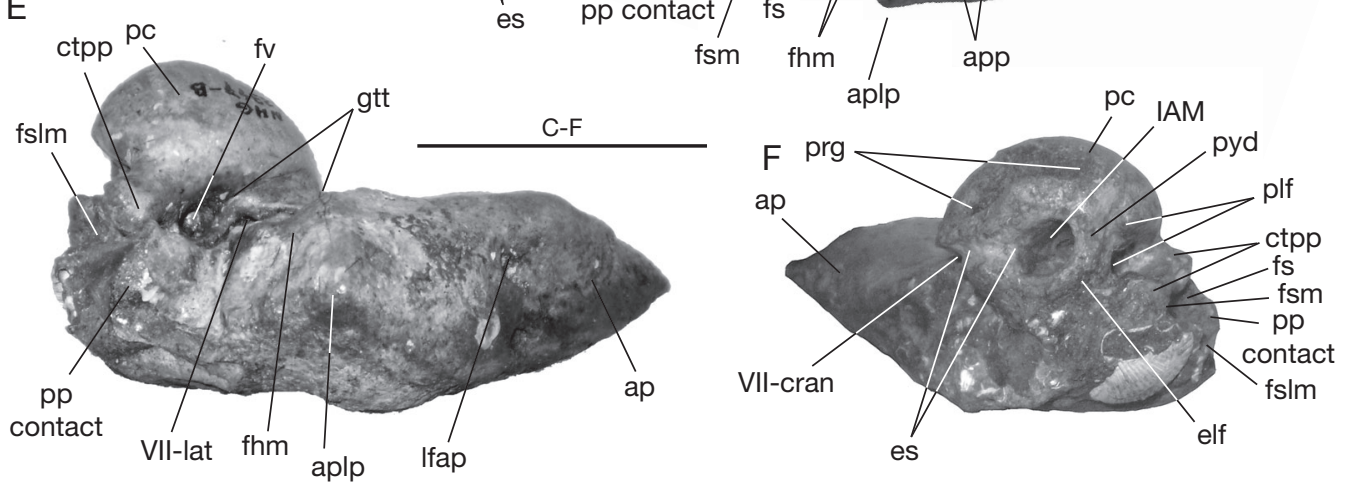

FIG. 10. - Diunatans luctoretemergo n. gen., n. sp., paratype NHG 22347-b: A, B, left periotic, MRI-scan, ventral view; A, line drawing; B, photograph; C, medial view, photograph; D, ventral view, photograph; E, lateral view, photograph; F, cranial view, photograph. Abbreviations: see p. 333,334 . Scale bars: $5 \mathrm{~cm}$. 
dorsal surface of the vertebral body. The lateral sides of the vertebral body are more posteriorly located than the central parts, resulting in a weak $\mathrm{V}$-shaped outline in dorsal view. The transverse processes of these vertebrae are missing; only the basal joints are preserved. The epiphyses show almost no trace of sutures and are well connected to the vertebral body (Figs 2-4; 7).

\section{STRATIGRAPHY}

The holotype and paratype specimens were trawled from an unknown locality in the Westerschelde, The Netherlands in 1938 (Fig. 1). Late Miocene-Mid Pliocene cetacean fossils have been trawled from three locations in the 1930s: De Wielingen, in front of Knokke (Fig. 1A); De Griete and De Braakman near Terneuzen (Fig. 1B) and along the riverbank near Borsele and Ellewoudsdijk (Fig. 1C).

The damaged edges of the holotype skull reveal that it must have been fairly complete and that rostrum, frontals and postcrania must have been damaged during dredging. The absence of wear caused by reworking or secondary transportation, the presence of both petrotympanic complexes, and the position of the cervical vertebrae in articulation, indicate that the skeleton was fairly completely preserved, on or near the river bed.

Miocene and Pliocene fossils of marine mammals, as well as (to a lesser extent) Late Pleistocene fossils of terrestrial and marine mammals, are known from the Westerschelde (Drees 1986; Ebbing et al. 1993). The Miocene and Pliocene fossils originate from the Antwerpen Sand Member (Middle Miocene), the Deurne Sand Member (Late Miocene), the Kattendijk Sand Member (Early Pliocene), the Luchtbal Sand Member (late Early Pliocene) and the Oorderen Sand Member (Middle Pliocene) and are reworked from these strata by the eroding river Schelde (Drees 1986; Ebbing et al. 1993).

Parts of the original matrix in which the holotype skull was embedded, are still attached to the cranium and between the vertebrae. From this cemented, coarse and sandy matrix seven species of molluscs were collected (Appendix 4). Three molluscs (Calyptrea chinensis (Linnaeus, 1758), Arctica islandica (Linnaeus 1767), and Corbula gibba gibba (Olivi, 1792)) occur from the Miocene onwards, and therefore do not provide specific stratigraphic information (Marquet 1998, 2005). Parvicardium scabrum (Philippi, 1844) also encompasses a wide stratigraphic timeframe (Pliocene to Recent), but is not known from Miocene strata (Marquet 2005). Ringicula buccinea (Brocchi, 1814) is of Miocene to Early Pliocene occurrence and the sample strongly resembles the more archaic morphology of the species. Compared to Middle and Late Pliocene specimens, it is smaller, has a narrower outer lip and a more shallow suture. This morphology also occurs in the Kattendijk Formation (Early Pliocene) at Schijnpoort, Antwerpen, Belgium (Marquet 1998). Middle Pliocene or younger records of this species in the North Sea basin are not known. Isocrassina omalii (de la Jonkaire, 1823) is a bivalve which is typical for the Early Pliocene (Kattendijk and Luchtbal Sand Members) and scarce finds are known from the basal crags of the Middle Pliocene (Oorderen Sand Member) but seem reworked (Marquet 2005). Thracia altenai Glibert \& van de Poel, 1966 occurs from the Early to the Middle Pliocene (Marquet 2005). The absence of Palliolum gerardi (Nyst, 1835) seems noteworthy since this species is extremely common in the late Early Pliocene Luchtbal Sand Member.

Taking all evidence into account, an Early Pliocene (Zanclean; between 5.0 Ma and 4.7-4.4 Ma; Louwye et al. 2004) origin of this cranium is assumed.

In the Schelde estuary, Early Pliocene strata were deposited in a near coastal environment with a water depth of probably less than $25 \mathrm{~m}$ because fossil Balanus species are common on Antwerp cetacean bones from the Kattendijk sands (pers. obs.). Seasurface temperatures were cool to temperate (less than $7.2^{\circ} \mathrm{C}$ for April sea-surface temperatures) (Gaemers 1988; Louwye et al. 2004; Lambert 2007).

\section{DISCUSSION}

One of the most remarkable features of $D$. luctoretemergo n. gen., n. sp. is the enormous size of its bulla. Relative to the zygomatic width of the cranium, it is the largest known bulla of the family. In absolute terms it is of similar size as the bulla of the extant fin whale $B$. physalus, which is, however, about 
A

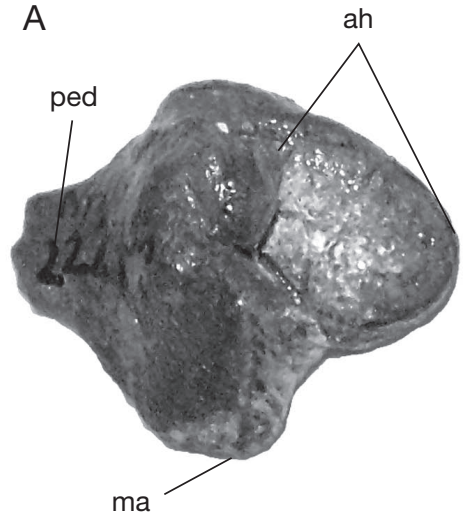

B

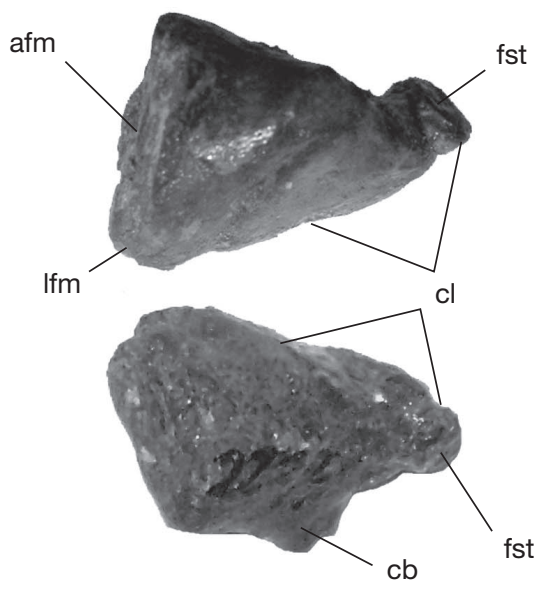

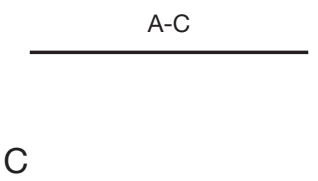

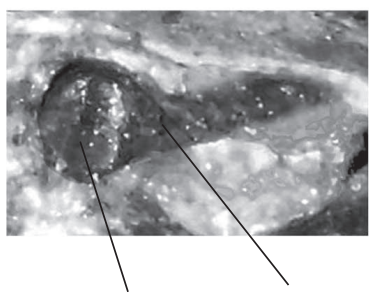

fai

sf?



FIG. 11. - Diunatans luctoretemergo n gen., n. sp., holotype NHG 22279, left auditory ossicles and periotic, photographs: A, malleus (NHG 22279-d); B, incus (NHG 22279-e); C, stapes (NHG 22279-a); D, periotic (NHG 22279-a). Abbreviations: see p. 333, 334. Scale bars: A-C, $1 \mathrm{~cm} ; \mathrm{D}, 5 \mathrm{~cm}$. 


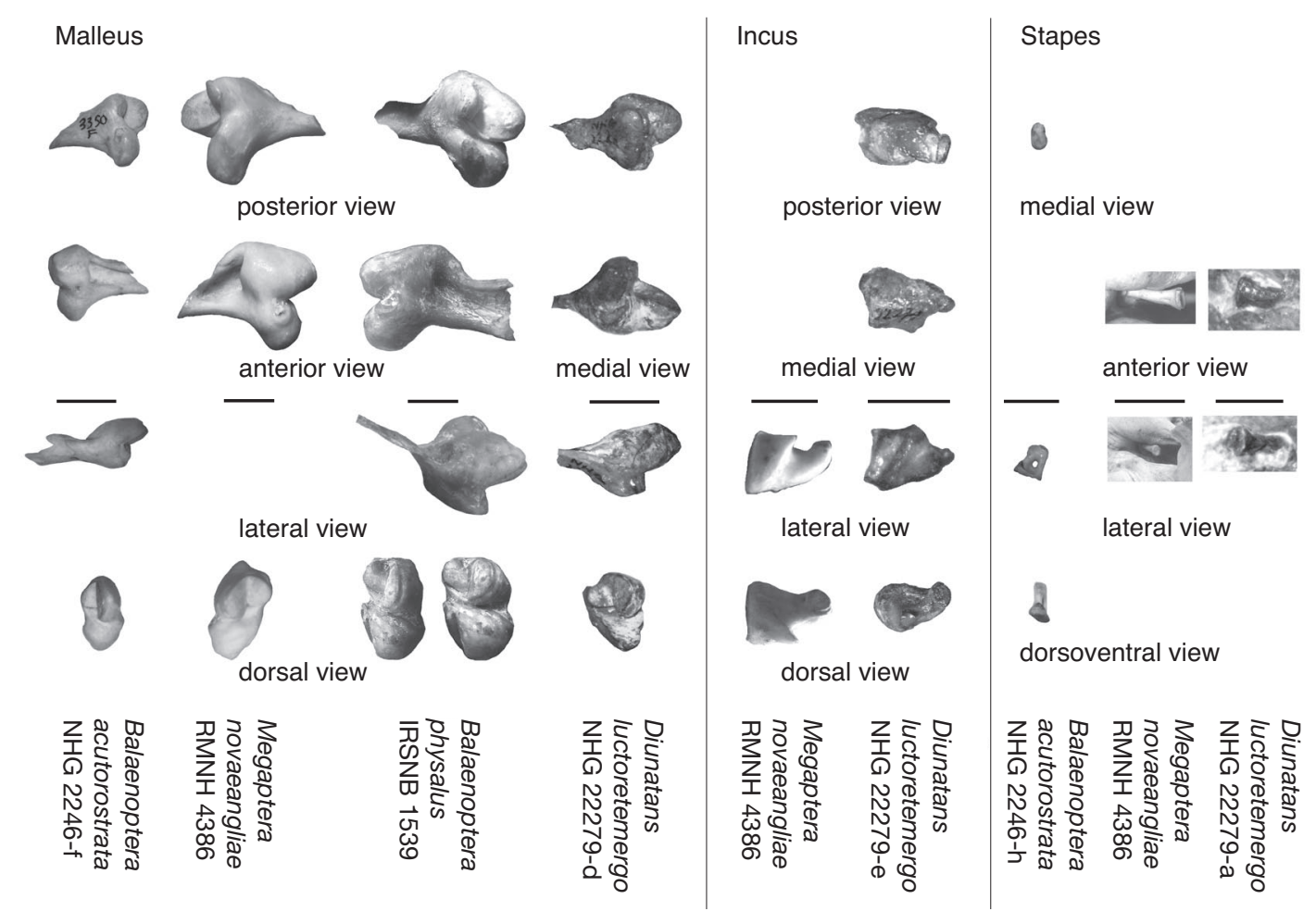

FIG. 12. - Auditory ossicles of the holotype of Diunatans luctoretemergo n. gen., n. sp. (NHG 22279-e) compared to those of some extant species. Scale bars: $1 \mathrm{~cm}$.

twice the estimated body size of $D$. luctoretemergo n. gen., n. sp. Another remarkable feature of the bulla is the perpendicular direction of the sigmoid process because in extant rorquals an inclination of $c .17 \%$ (with respect to its longitudinal axis) is noted. The periotic is very robust and the stapes is unusually long. The crista petrosa leading to the posterior process is unusually stocky and thick, and its angle towards this process is the largest of the family. The facial nerve canal continues over the mediodorsal side of the crista transversa, towards the acoustic meatus, to the extent that the endocranial foramen for the facial nerve and the internal acoustic meatus are interconnected by a deep, long and narrow sulcus, running over the crista transversa in anteroposterior direction. We could observe the same "primitive" architecture on the periotic of B. physalus (IRSN reg. 1539), a rather exceptional feature in extant Balaenopteri- dae (Bisconti, pers. comm.), and on the periotic of the Miocene mysticete Mesocetus longirostris Van Beneden, 1880 (IRSNB M 548), in which species this condition is always present (pers. obs.). The extreme dimensions of bulla and periotic seem to be directly linked to an unusually large and wide pterygoid fossa, while the extraordinary length of the stapes of $D$. luctoretemergo n. gen., n. sp. may be linked to the unusually rounded pars cochlearis. We presume the big, globose bulla and the long, slender stapes may enhance the resonance and/or favour the transmission of low frequencies and thus may favour low frequency long distance hearing.

Whether or not (some of) these features will prove to be autapomorphic characters of this species must be checked by future research on basal balaenopterids. Either way, all mentioned features are in remarkable contrast to those observed in other Early Pliocene rorquals. Work on fossil Balaenopteridae from the 


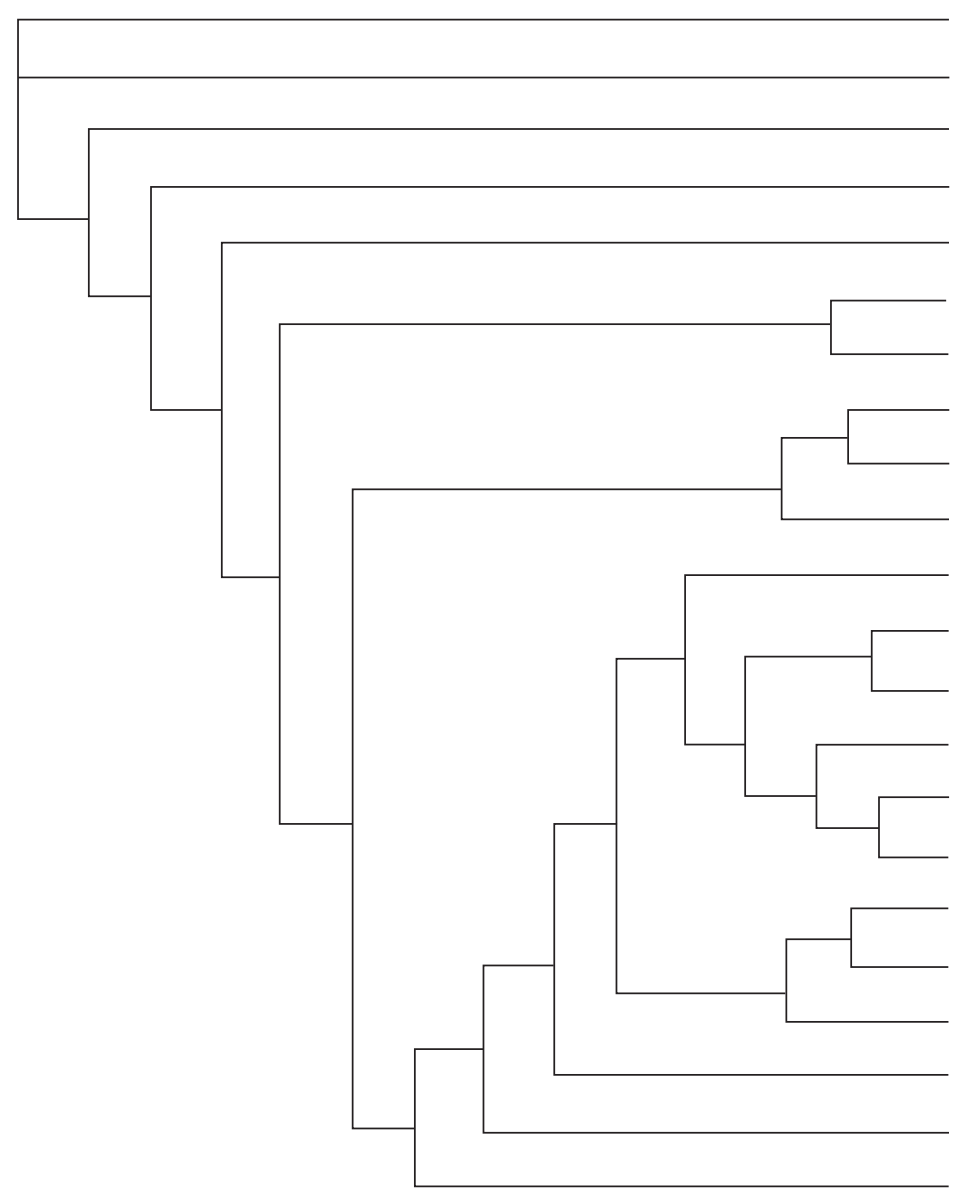

Protocetus atavus

Georgiacetus vogtiensis

Zygorhiza kochii

Aetiocetus polydentatus

Eomysticetus whitmorei

Pelocetus calvertensis

Parietobalaena palmeri

Cetotherium rathkei

Mixocetus elysius

Eschrichtius robustus

Balaenoptera acutorostrata

Balaenoptera physalus

Balaenoptera musculus

Balaenoptera borealis

Balaenoptera edeni

Balaenoptera omurai

Megaptera novaeangliae

Megaptera miocaena

Megaptera hubachi

Diunatans luctoretemergo

n. gen., n. sp.

"Plesiocetus" cortesii

MPST 240505

FIG. 13. - Phylogenetic relationship of Diunatans luctoretemergo n. gen., n. sp., most parsimonious tree. Tree length: 326 steps; consistency index $(\mathrm{Cl})$ : 0.6963; retention index: 0.8361; homoplasy index: 0.3037 ; rescaled $\mathrm{Cl}$ : 0.5822 .

North Sea (Bisconti et al. unpubl. data) shows that plesiomorphic architectures of the vertex seem to coincide with relatively smaller petrotympanic complexes (see also Steeman 2004; Bisconti 2007). It appears that there was high morphological variation in the petrotympanic complex in Balaenopteridae at the time the genesis of modern balaenopterid genera took place and therefore the morphology of the petrotympanic complex in extant rorquals presumably represents the derived condition.

Small and broad nasals also constitute a derived feature. While most of the fossil Miocene and Early Pliocene mysticetes show long and slender nasals, the position of the nasal opening of $D$. luctorete- mergo n. gen., n. sp. is located close to the supraoccipital, at a slightly more anterior position than in extant rorquals. The morphology and position of the nasals more or less resembles that of $B$. physalus, $B$. musculus and $M$. novaeangliae but differs from $B$. acutorostrata, B. omurai, B. edeni and B. borealis (Bisconti, pers. comm.).

The squamosal shows a mix of derived and primitive features. Although the general morphology is as in modern rorquals (concave condylar surface, low and enlarged zygomatic arch). In posterior view the squamosal is mediolaterally robust and wide, lateral to the supraoccipital, and it has a typical dorsal bulge. 
The morphology of the occipital condyles shows plesiomorphic features. They are very prominent, relatively very large, and differ completely from $B$. acutorostrata but resemble slightly the condition seen in the extant humpbackwhale. Extant rorquals of the genus Balaenoptera all possess relatively small condyles which articulate in a flat surfaced atlas. The condyles of $D$. luctoretemergo n. gen., n. sp., however, are backwards protruding to an atlas which is concave with prominent borders. Also the next three cervical vertebrae show concave surfaces and, in dorsal view, a $\mathrm{V}$-shape. The morphology of atlas and condyle of extant rorquals may be directly related to their specialized way of feeding (engulfment and intermittent ram-feeding), which obviously does not necessitate extensive lateral and vertical movements of the cranium. The Gray whale Eschrichtius robustus (Lilleborg, 1864), on the contrary, exploits a totally different feeding method (benthic side-happing) and shows, besides rugosities for muscle attachments on the supraoccipital, also very prominent and large condyles and a more arched atlas surface. Hence it may be not too far fetched to presume that the aberrant condyles and the morphology of the cervical vertebrae of $D$. luctoretemergo n. gen., n. sp. imply a good mobility of the neck.

\section{PHYLOGENETIC ANALYSIS}

The phylogenetic analysis was caried out using the matrix published by Bisconti (2008). The original matrix uses 165 characters, scored for 35 taxa. For the current analysis the number of taxa was reduced to 22 (including D. luctoretemergo n. gen., n. sp.), omitting all Balaenidae and some Cetotheriidae. "Balaenoptera" siberi is not included in the analysis. As explained in the differential diagnosis this taxon shows characters basal to the Balaenopterinae and the Megapterinae and therefore is certainly not belonging to the genus Balaenoptera. Work in progress (Bisconti, pers. com.) will clarify its phylogenetic position. Diunatans luctoretemergo n. gen., n. sp. scores 110 of the 165 characters, 55 characters cannot be scored because the anatomical elements concerned are not preserved. The 165 characters are scored as follows:
Diunatans luctoretemergo n. gen, n. sp.

111?1??1?? 11?????01? ?1121?1112 1??2022???

00020000?? ??310?011? 115?11??1? 21?112010?

212?32111? 10??????11 010?2????? 2221021101

?110?200?? 10001000?0 ?00000?001 0?101220??

$0011 ?$

The cladistic analysis was carried out with PAUP 4.0b10 (Swofford 2002) using Protocetus atavus Fraas, 1904 and Georgiacetus vogtlensis Hulbert, Petkewich, Bishop, Bukry \& Aleshire, 1998 as outgroup. Character states were treated as unordered. The search for the most pasimonious cladograms was made by tree-bisection-reconnection (TBR) with 5000 replicates. The TBR search found one island of trees, containing one cladogram which was 326 steps long, the consistency index is 0.6963 , the retention index is 0.8361 , the homoplasy index 0.3037 and the rescaled consistency index 0.5822 . The (consensus) tree is presented in Figure 13. Diunatans luctoretemergo n. gen., n. sp. ends up as stem- balaenopterid, more derived than "Plesiocetus cortesii" and basal to both Balaenopterinae and Megapterinae. The main characters giving $D$. luctoretemergo n. gen., n. sp. its stem position are: squamosal bulged into temporal fossa (char. 4), internal opening of the facial canal small and tubular (char. 59), groove under the IAM present (char. 89), zygomatic process slightly divergent (char. 91), floor of stylomastoid fossa absent (char. 36) and groove for the tensor tympany muscle present (char. 148).

\section{CONCLUSIONS}

Diunatans luctoretemergo n. gen, n. sp is the first described fossil rorqual of the North Sea realm because the following fossil rorqual species described by Owen and Van Beneden must be considered nomina dubia (see Appendix 1): B. definata (Owen, 1844); B. emarginata (Owen, 1844); B. gibbosa (Owen, 1844); B. borealina Van Beneden, 1880; B. musculoides Van Beneden, 1880; B. rostratella Van Beneden, 1880; B. sibbaldina Van Beneden, 1880; Plesiocetus goropii Van Beneden, 1859; Megapteropsis robusta Van Beneden, 1872; Megaptera affinis Van Beneden, 1880. 
- Balaenoptera siberi cannot be considered a member of the genus Balaenoptera. It is a more basal rorqual which affinities and phylogenetic position need to be adressed.

- The genus Balaenoptera is limited so far to the known extant species: $B$. acutorostrata, $B$. bonaerensis, B. borealis, B. edeni, B. musculus, B. omurai and $B$. physalus.

\section{Acknowledgements}

We thank: Georges Lenglet (IRSNB), Annelise Follie (IRSNB), Eberhard Frey (Staatliches Museum für Naturkunde Karlsruhe) and Peter van Bree (Zoölogisch Museum Amsterdam) for access to the collections under their care; Robert Marquet (IRSNB), Peter Moerdijk (Nationaal Natuurhistorisch Museum Leiden; Koninklijk Zeeuws Genootschap der Wetenschappen, Middelburg) and Freddy van Nieulande (Nationaal Natuurhistorisch Museum Leiden; Koninklijk Zeeuws Genootschap der Wetenschappen, Middelburg) for identifications of molluscs and usefull comments; the staff of the Maria-Middelares Hospital (Antwerp) for the MRIscan of the periotic; Olivier Lambert (IRSNB), Jelle Reumer (Natuurhistorisch Museum Rotterdam) and Kees Hazevoet (Museo Nacionale de Historia Naturale, Lisboa) and Christiaan Hoedemaekers (Palaeo Publishing and Library) for frank comments and directions improving the article. T. A. Deméré (San Diego Institute of Natural History) provided information and C. de Muizon (Muséum national d'Histoire naturelle, Paris), M. E. Steeman (Museum Sønderjyllan, Gram, Denmark) and an anonymous reviewer significantly enhanced the quality of the final article. Last but not least we have to mention Michelangelo Bisconti (Museo di Storia Naturale del Mediteraneo, Livorno) because without our mutual and exciting discussions and his free exchange of ideas, this article could not have been written.

\section{REFERENCES}

Abel O. 1938. - Vorlaufige Mitteilungen über die Revision der fossilen Mystacoceten aus dem Tertiars Belgians. Bulletin du Musée royal d'Histoire naturelle
Belge 14 (1): 1-34.

BisCONTI M. 2007. - A new basal balaenopterid whale from the Pliocene of Northern Italy. Paleontology 50 (5): 1103-1122.

BISCONTI M. 2008. - Morphology and phylogenetic relationships of a new eschrichtiid genus (Cetacea: Mysticeti) from the Early Pliocene of Northern Italy. Zoological Journal of the Linnean Society 153: 161-186.

Bouetel V. \& De Muizon C. 2006. - The anatomy and relationships of Piscobalaena nana (Cetacea, Mysticeti), a Cetotheriidae s.s. from the early Pliocene of Peru. Geodiversitas 28 (2): 319-395.

DrEES M. 1986. — Kritische kanttekeningen bij de naam "Zwarte bottenfauna". Cranium 3 (2): 103-120.

De SMET W. M. A. 1978. - Beschouwingen over de fossiele Cetacea uit de omgeving van Antwerpen (België). Mededelingen Werkgroep Tertiaire en Kwartaire Geologie 15 (2): 37-51.

DemérÉ T. A. 1986. - The fossil whale Balaenoptera davidsonii (Cope, 1872) with a review of other Neogene species of Balaenoptera (Cetacea, Mysticeti). Marine Mammal Science 2: 277-298.

Deméré T. A., Berta A. \& McGowen M. R. 2005. The taxonomic and evolutionary history of fossil and modern balaenopteroid mysticetes. Journal of Mammalian Evolution $12(1+2)$ : 99-143.

Ebbing J. H. J., Laban C., Frantsen P. J. \& Nederhof H. P. 1993. - Rabsbank, Sheet 51'20"N-3'00"E, 1:100.000 series. Rijks Geologische Dienst, The Netherlands.

GARDNER A. L. \& Hayssen V. 2004. — A guide to constructing and understanding synonymies for mammalian species. Mammalian Species 739: 1-17.

GAEMERS P. A. M. 1988. — The regional distribution of otolith assemblages; correlation of the interregional zonation with the regional lithostratigraphic formations, in VINKEN R. (ed.), The Northwest European Tertiary Basin. Geologisches Jahrbuch, Reihe A 100: 369-379.

GeisLer J. H. \& LuO Z. 1996. - The petrosal and inner ear of Herpetocetus sp. (Mammalia, Cetacea) and their implications for the phylogeny and hearing of archaic mysticetes. Journal of Paleontology 70 (6): 1045-1066.

KeLLOGG R. 1922. - Description of the skull of Megaptera miocaena, a fossil humpback whale from the Miocene diatomaceous earth of Lompoc, California. Proceedings of the United States National Museum 61: 1-18.

LAMBERT O. 2007. - A monodontid cetacean from the Early Pliocene of the North Sea. Bulletin van het Koninklijk Belgisch Instituut voor Natuurwetenschappen \& Aardwetenschappen 77: 197-210.

Louwye S., Head M. J. \& De SChepper S. 2004. Dinoflagellate cyst stratigraphy and palaeoecology of the Pliocene in northern Belgium, southern North Sea Basin. Geological Magazine 141 (3): 353-378. 
LYDEKKER R. 1887. - The cetacea of the Suffolk Crag. Quaterly Journal of the Geological Society of London 43: 7-18.

MARQuet R. 1998. - De Pliocene Gastropodenfauna van Kallo (Oost-Vlaanderen, België). Belgische Vereniging voor Paleontologie 17: 246.

MARQUET R. 2005. - The Neogene Bivalvia (Heterodonta and Anomalodesmata) and Scaphopoda from Kallo and Doel (Oost-Vlaanderen, Belgium). Paleontos 6. Palaeo Publishing and Library: $142 \mathrm{p}$.

OWEN R. 1844. - Appendix to Professor Henslow's paper, consisting of a description of the fossil tympanic bones referable to four distinct species of Balaena. Proceedings of the Geological Society of London 4: 37-40.

Oishi M. \& HASEGAWA Y. 1994. - Diversity of Pliocene mysticetes from eastern Japan. The Island Arc 3: 436-452.

PORTIS A. 1885. - Catalogo descrittivo dei Talassoterii rinvenuti nei terreni terziari del Piemonte e della Liguria. Memorie della Reala Academia della Scienze di Torino 37: 247-365.

SLIJPER E. J. 1936. — Die Cetaceen, vergleichend - anatomisch und systematisch. Capita Zoologica 7: 1-590.

SteEman M. E. 2004. - Description of Uranocetus gramensis gen. et sp. nov. (Cetacea: Mysticeti) from the late Miocene Gram Formation, Denmark, Revision of
Mysticete Classification and Extinct Belgian Mysticetes. Unpublished PhD thesis, University of Copenhagen, Denmark, 2 volumes, volume 1, 112 p.; volume 2, $110 \mathrm{p}$.

STEEMAN M. E. 2007 - Cladistic analysis and a revised classification of fossil and recent mysticetes. Zoological Journal of the Linnean Society 150: 875-894.

SwOFFord D. L. 2002. - PAUP*. Phylogenetic analysis using parsimony (*and other methods). Version 4.0b10 (Alvitec). Sinauer Associates, Sunderland, Massachusetts.

True F. W. 1912. - The genera of fossil whalebone whales allied to Balaenoptera. Smithsonian Miscellaneous Collection 59 (6): 1-8.

VAN BENEDEN P. J. 1872. — Les baleines fossiles d'Anvers. Bulletin de l'Académie des Sciences de Belgique 2 (34): 6-20.

Van Beneden P. J. 1880. — Les Mysticètes à courts fanons des sables des environs d'Anvers. Bulletin de l'Academie des Sciences de Belgique 2 (50): 11-27.

VAn Beneden P. J. 1882. - Description des ossements fossiles des environs d'Anvers. Annales du Musée d'Histoire Naturelle de Belgique, Tome III.

WINGE H. 1921. - A review of the interrelationships of Cetacea. Smithsonian Miscellaneous Collection 72 (8): 1-97. 


\section{APPENDIX 1}

Review of and comments on the fossil rorquals described by Owen and Van Beneden.

In the course of this study, the historical type material of Owen and Van Beneden was examined for comparison. Due to the fragmentary state of most of the specimens, a revision proved to be necessary. Indeed the atlases of Van Beneden are still widely used as reference for the taxonomy and anatomy of Neogene mysticetes from the North Sea.

Several taxa named by Owen and Van Beneden were, and still are, the subject of intense debate. As stated in the introduction, the result is "taxonomic paralysis” (Deméré et al. 2005). Herein we will at last re-evaluate and revise the rorquals (Balaenopteridae) described by Owen and Van Beneden. Although Owen's taxons were already declared nomina dubia (Deméré et al. 2005), we included them again in this study because of their historical close link with the species described by Van Beneden. In order to do so, we have visually inspected all relevant fossils and compared them to the original descriptions and illustrations. Our goal is to analyse whether or not the descriptions are based on fossils of various individuals, and if so, whether there exists morphological diversity between these individuals and if this diversity might be explained by ontogeny or by mixing of different species and/or higher rank taxa. Our conclusions will be compared with those of the original authors, taking into account their diagnoses, descriptions and plates. If their views can be confirmed, existing taxonomy will be retained. If our conclusions are different, we either designate a specimen as lectotype if a particular fossil possesses sufficient diagnostic characters, or otherwise deem the nominal taxon a nomen dubium.

In 1844 Owen named four fossil whales based on four isolated bullae found in the Red Crag of Felixtow, Suffolk. In his short paper, Owen (1844: 37) stated that the specimens are "rolled and water worn" and that "none of them is entire". By comparing the specimens to bullae of delphinids, ziphiids, physeteriids and "true whales", Owen concluded that they seemed close to true "Balaena"; he named four new species and illustrated one of them (Balaena affinis). Upon re-inspecting these tympanics, Lydekker (1887) realised that three of the bullae showed balaenopterid features and included these in the genus Balaenoptera (B. definata (Owen, 1844), B. emarginata (Owen, 1844) and B. gibbosa (Owen, 1844)). Lydekker also visited Brussels to study the newly published Belgian specimens and to discuss fossil cetaceans with Van Beneden. He politely commented about the Van Beneden nomenclature: "It appears to me that some of the generic divisions are unnecessary, and I cannot help thinking that in certain instances some of the forms to which specific names have been applied are not improbably only individual or sexual variations; but as it is impossible to prove this, I cannot but adopt such species", and in a footnote to the same sentence: "In many instances it does not appear to me by any means certain that the vertebrae belong to the same species as the tympanics, and it is therefore advisable to regard the latter as the type of such species" (Lydekker 1887: 10, 11). He considered B. definata different from all the Brussels tympanics and therefore a separate and valid species. Balaenoptera emarginata and B. gibbosa he valued to be one and the same species, because the different morphology of the involucrum, on which the latter species was based, is age-related. Moreover, he concluded that these tympanics were "absolutely indistinguishable" from the tympanics of $B$. rostratella Van Beneden, 1880, and that therefore Owen's name should have priority (Lydekker 1887: 12)

The bullae are weathered, rounded and fragmentary, show general balaenopterid features, but lack diagnostic features at the species or genus level and in conclusion, we concur with Deméré et al. (2005) and consider Owen's three nominal rorqual species as nomina dubia.

In a series of short papers, Van Beneden (1872, 1880) named a large number of new mysticetes without giving diagnostic features or collection numbers. Holotypes were not selected, nor illustrations given. In his 1882 work he elaborates again on these species, presented more specific information for some 
fossils, gave collection numbers and provided excellent illustrations.

While describing B. musculoides, Van Beneden (1882: 67) explained his working method. By combining vertebral columns, he found four or five "different forms", which he considered to be different species. Thereafter he concentrated on the fossils of atlas and axis and found "more or less" the same variation. The method was then applied to bullae ("hundreds, if not thousands"), and the result was "more or less" identical; therefore, he decided to give a name to each "form". He then realised that the fossil forms were "more or less" the equivalent of extant rorquals, hence he invented names referring to the corresponding extant rorquals. On page 71, while describing the periotic of $B$. borealina, it appears that Van Beneden considered the shape of the posterior process of the periotic a diagnostic feature at the species level.

We will reassess the rorquals named by Van Beneden following the order of appearance in his 1882 work.

\section{MEGAPTEROPSIS ROBUSTA VAN BENEDEN, 1872/ MEGAPTERA AFFINIS VAN BENEDEN, 1880}

Van Beneden (1882) considered both names as synonyms and gave some rather subjective reasons for the change of name. Deméré et al. (2005) clarified that the former name has priority over the latter.

The description mentions that the museum possesses "a complete mandible, a rostrum fragment, bullae, cervical, thoracic and caudal vertebrae, some ribs and a caput of a humerus", originating from six different sites (Van Beneden 1882: 39). The illustrations (plates 40-48) show (in order of appearance): the mandible (M 810), a third thoracic vertebra (M 815), a 13th thoracic vertebra (M 816), a distal fragment of a left maxilla (M 807), a periotic (M $809 \mathrm{a})$, the fifth and sixth phalanx of the third finger of the left arm (M 809c-d), a bulla (M 808), an atlas (M 812), the posterior process of the periotic (M 809b), an axis (M 813), a fifth cervical vertebra (M 814), a third caudal vertebra (M 817), a fifth caudal vertebra (M 818), a sixth caudal vertebra (M 819), an 11th caudal vertebra (M 824), an eighth caudal vertebra (M 820), a 12th caudal vertebra (M 821), a 14th and 16th caudal vertebra (M $822 \mathrm{a}+\mathrm{b})$, an 18 th caudal vertebra
(M 823), a first left rib (M 811 a), and a fourth left rib (M 811 b).

According to the "estimation" of Mr De Pauw (Van Beneden's assistant) these fossils might have belonged to 28 individuals, of which two individuals must have been juvenile (Van Beneden 1882: 39). The most complete fossil, mandible M 810, is described in detail and clearly confused Van Beneden. Based on the length of this mandible $(2.94 \mathrm{~m})$, he estimated the total length of $M$. robusta to be $16-17 \mathrm{~m}$.

\section{Observations}

- No holotype is designated;

- none of the described or figured elements, or part of them, have been found together or may with reasonable certainty - be assigned to one and the same individual. Specific details (such as "fifth phalange of third left finger") are therefore based on speculation;

- the described and illustrated ribs, elements of the manus, and vertebrae do not show diagnostic and/or derived characters to warrant assignment at generic or specific level;

- the bulla (M 808) is eroded and damaged. Feeble balaenopterid features are recognisable (e.g., simple main ridge), but it is too damaged to show any specific characters allowing assignment at generic or specific level;

- the periotic (M 809) is better preserved and shows clearly general features of the Balaenopteridae (e.g., triangular anterior process, shape of pars cochlearis), but does not show autapomorphies allowing specific identification;

- the maxillary fragment shows no characteristic features at all;

- the mandible is a fine specimen, but bears multiple eschrichtiid features (Deméré et al. 2005) and therefore cannot be assigned to the Balaenopteridae. In fact this mandible shows a remarkable resemblance to "Balaenoptera" gastaldii (Portis, 1885) (cf. Bisconti 2003, 2006, 2007).

\section{BALAENOPTERA SIBBALDINA VAN BENEDEN, 1880}

Van Beneden (1882: 63) stated that he created four fossil species in the genus Balaenoptera based on "the size and characters of the bones in line with the four extant species" and also that he "realises that 
some scholars might call his identifications of the bones more or less arbitrary". However he assures that the job is done with great care.

The largest rorqual to be named was named B. sibbaldina. Of this species the museum possesses: "a damaged occipital, two parietal fragments, six periotics, five bullae, five thoracic, two lumbar and six caudal vertebrae, and a rib fragment", originating from seven different sites (Van Beneden 1882: 63). The illustrations (plates 49-51) show - in order of appearance - a damaged occipital with petrosal fragments of a "foetus" (M $736 \mathrm{a}-\mathrm{c}$ ), the anterior process and pars cochlearis of a periotic (M 737), a posterior process of a periotic (M 738), a second thoracic vertebra (M 739), the proximal joint of the fourth left rib (M 740), a frontal (M 748), a tenth thoracic vertebra (M 741), a 14th lumbar vertebra (M 742), a third caudal vertebra (M 743), a sixth caudal vertebra (M 744), a ninth caudal vertebra (M 745), a 16th caudal vertebra (M 746), and a 17 th caudal vertebra (M 747).

\section{Observations}

- No holotype is designated;

- none of the described or figured elements, or part of them, have been found together or may - with reasonable certainty - be assigned to one and the same individual;

- specific details (such as "fourth left rib") are therefore based on speculation;

- the described and illustrated ribs, elements of the manus, and vertebrae do not show diagnostic and/or derived characters to warrant assignment at generic or even higher level;

- M736 a-c is indeed from a very young individual. It is a severely damaged supra- and exoccipital with attached fragments of the squamosal. The glenoid and falciform process of the squamosal are not preserved. A fragment of the posterior process of the periotic, and two fragments of pars cochlearis are preserved. Unfortunately none of the elements bears diagnostic characters and undisputable general balaenopteroid characters cannot be confirmed. Therefore its assignment to a foetus of a specific rorqual species is not correct;

- M 737 is a periotic of gigantic size. Unfortunately it is severely damaged. The ventral surface of the pars cochlearis is completely gone, leaving some part of the facial nerve canal and acoustic meatus visible. Probably this periotic belongs to a balaenopterid, but real diagnostic characters for specific identification are not available.

\section{Plesiocetus goropit Van Beneden, 1859/}

BalaENOPTERA MUSCULOIDES VAN Beneden, 1880 Van Beneden merely mentioned that he changed the previous name (in honour of Mr. Van Gorp) to the latter, due to the availability of plentiful fossils. He specifically mentioned that this mysticete (together with $B$. rostratella) is the most common fossil Belgian mysticete, that it is also found in Italy, and that it is easy to recognise, based on bulla, periotic and even vertebrae. The fact that several vertebrae of one individual have been preserved is also underlined.

Of this taxon the museum possesses: "a mandible, a more or less complete vertebral column, different bones of the manus, a large number of bullae, periotics, fragments of the skull, ribs, etc." from six different locations (Van Beneden 1882: 66).

The illustrations (plates 51-65) show (in order of appearence): "a vertebral column, composed from six individuals (Reg 154- possibly lost-, M 806, 767a-c, 766, 770,769): seven cervical, 11 thoracic, 11 lumbar, and 17 caudal vertebrae, a left dentary (M 690), a condyle of a dentary (M 730), a 12th right rib, isolated bullae ( $\mathrm{M} 753,750,751)$, an occipital fragment (M 749), a bulla, the seventh cervical, the first three and 24th thoracic and the 24th caudal vertebra, a fragment of a scapula of one individual (M $754 \mathrm{a}-\mathrm{i}$ ), a bulla and a complete periotic of one individual (M 752a-e), a humerus (M 763), an atlas and axis of one individual (M 756), an atlas, the second to seventh cervical vertebrae, a second, fifth and tenth thoracic vertebra of one individual (M 755a-i), a 20th caudal vertebra (M 770), an atlas (M 758), a damaged right radius ( $M$ 764), an atlas ( $M$ 757), an axis (M 767b), a 14th thoracic vertebra (M 760), a seventh lumbar vertebra (Reg 154 - possibly lost), a ninth caudal vertebra (M 762), a ninth lumbar vertebra (M 761) and a 12th caudal vertebra (M 770)". 


\section{Observations}

- No holotype is designated;

- some of the described or figured elements have been found together and might derive from one and the same individual, but unfortunately none of the associated elements, or their association, carries diagnostic value at the species level;

- specific details (such as "12th right rib") are based on speculation;

- the described and illustrated ribs, elements of the manus, and vertebrae do not show diagnostic and/or derived characters to warrant assignment to specific, generic, or even higher taxonomic level; - while most of the bullae seem alike, a few are clearly different and do belong to a different taxon (M 751, M 753);

- mandible M 690 is a very nice specimen. This mandible shows features of undescribed balaenopterids from Antwerp (pers. obs.) and basal balaenopterids from Italy (cf. Bisconti 2007). Complete mandibles do carry important information on feeding strategies and these characters might be sufficient to warrant family - or even generic assignment. However we do not consider a mandible only sufficient to base a new rorqual species on (or to choose a lectotype).

\section{BALAENOPTERA BOREALINA VAN BENEDEN, 1880}

Besides a general remark that the name of this fossil rorqual is based on the close resemblance with extant $B$. borealis, no information is provided by the author.

Of this species the IRSNB possesses: "a mandible, a more or less complete vertebral column, different bones of the manus, a fragment of a rib, a fragment of the cranium, a bulla, a periotic, etc." (Van Beneden 1882: 71). Van Beneden mentioned that the museum collection stored these elements "at least 15-times". No site or location of the fossils is mentioned, but the labels of the fossils mention specific sites.

The illustrations (plates 66-75) show (in order of appearance): "a left mandible (M 771), an occipital fragment (M 772), two left bullae (M 777, M 774), a left bulla with periotic fragment (M 775a-b), a right bulla (M 776), a left periotic (M 778), an atlas of a juvenile individual (M 779), a left ra- dius (M 773), an atlas (M 780), an axis (M 782), an atlas (M 781), a humerus (M 788), a right ulna fragment (M 789), a vertebral column of seven cervical and five thoracic vertebrae (M 783 a-1), a tenth thoracic vertebra (M 784), an eighth caudal vertebra (M $785 \mathrm{a})$, a 14th and 19th caudal vertebra (M787 a-b), a sixth lumbar vertebra (M 785 b), a second caudal vertebra (M 786)".

\section{Observations}

- No holotype is designated;

- none of the described or figured elements, except the part of a vertebral column, have been found together or may - with reasonable certainty - be assigned to one and the same individual;

- most specific details (such as "tenth thoracic vertebra") are therefore based on speculation;

- the described and illustrated ribs, elements of the manus, and vertebrae do not show diagnostic and/ or derived characters to warrant assignment to the generic, or even higher taxonomic level;

- mandible M771 is indeed a fairly complete mandible. However essential characters such as coronoid process or total length are not available;

- the bullae are clearly showing balaenopterid features. M $775 \mathrm{a}+\mathrm{b}$ is is particulary well-preserved petrotympanic complex showing most of the essential characters. Bisconti (2007) uses this complex in a broad phylogenetic exercise concluding that $B$. borealina is certainly not belonging to the genus Balaenoptera but to a more basal tribe. Such individual complexes might have generic importance but, in our opinion, should not be considered as a solid base for describing a new species or assigning a lectotype (see introduction).

BALAENoptera ROSTRatella VAN BENEDEN, 1880 Van Beneden (1882: 73) only mentioned that he gave the name because "several characters" of this fossil rorqual are close to extant B. acutorostrata. He reported a complete skeleton and mentioned that several elements of this rorqual are "repeated more than thirty times". The cranium is represented by a great number of fragments, and "thanks to" a more or less complete mandible, the cranium may be reconstructed. Collecting localities are not mentioned in the text, but the labels of the fossils mention spe- 
cific sites. The illustrations (plates 75-86) show (in order of appearance): "a damaged mandible (M790 a-b), cranial fragments (M 796a, 825 and 799), a distal fragment of a left mandible (M 792), bullae (M 796b, 798, 797, 795), a left periotic (M 794), a posterior process of a right periotic (M 793), a left humerus (M 803), a left scapula (M 802), a right radius (M 805), a fragment of a left ulna (M 804), atlas, axis, the third to seventh cervical-, the first to sixth thoracic, the ninth to 11th thoracic vertebrae, the first lumbar, the first, second, sixth and 12th caudal vertebra of one individual (M 791a-v), and a ninth caudal vertebra of a juvenile individual (M 801)".

\section{Observations}

- No holotype is designated;

- none of the described or figured elements, except a reasonably complete vertebral column, have been found together or may - with reasonable certaintybe assigned to one and the same individual;

- most specific details (such as "ninth caudal vertebra") are therefore based on speculation;

- the described and illustrated ribs, elements of the manus, and vertebrae do not show diagnostic and/or derived characters to warrant assignment to the generic - or even higher level;

- the vertebral column (M $791 \mathrm{a}-\mathrm{v})$ is fairly well preserved but is not accompanied by cranial material or elements of the manus;
- cranial fragment (M 799, a damaged vertex) shows a rounded parietal on top of the vertex, thus confirming that the fragment belongs to a basal mysticete;

- all cranial fragments (including M 799) are very fragmentary, and do not bear diagnostic or derived characters;

- mandible M 790 a-b is fragmentary and severely damaged, essential characters (coronoid process and parts of the symphysis) are missing;

- bulla M 798 belongs to a different taxon;

- periotic M794 is too damaged to show essential features.

\section{CONCLUSION}

Van Beneden might have considered the combination of various non-associated fossils and individuals as typical for a species. Moreover, sometimes, elements of various higher ranking taxa were grouped together within a species.

None of the individual fossils bears enough diagnostic features to be selected as lectotype.

Therefore $M$. robustal $M$. affinis, $B$. sibbaldina, P. goropii/B. musculoides, B. borealina, B. rostratella are based on non-diagnostic material from different individuals of possibly different higher level taxa and must be considered nomina dubia. 


\section{APPENDIX 2}

IRSNB "Anciens numéros de registre" (historical register numbers) and "Numéros Types et Figurés" (new catalogue numbers). Conversion of old IRSNB register numbers into new IRSNB collection numbers.

\begin{tabular}{|c|c|c|c|}
\hline Historical register numbers & New catalogue numbers & Historical register numbers & New catalogue numbers \\
\hline R 0011 & M 690 & R 0354 & M 805 \\
\hline R 0015 & M $756 a, b$ & R 0363 & M 809 a-d \\
\hline R 0016 & M 755 a-i & R 0367 & M 774 \\
\hline R 0022 & M $796 a, b$ & R 0368 & M $775 a, b$ \\
\hline R 0025 & M $754 a-i$ & R 0521 & M 806 \\
\hline R 0040 & M 772 & R 0522 & M 767 a-c \\
\hline R 0047 & M 791 a-v & R 0533 & M 812 \\
\hline R 0090 & M 784 & R 0538 & M 766 \\
\hline R 0107 & M $785 a, b$ & R 0560 & M 807 \\
\hline R 0136 & M 738 & R 0561 & M 817 \\
\hline R 0139 & M 818 & R 0562 & M 824 \\
\hline R 0140 & M 819 & R 0611 & M 740 \\
\hline R 0141 & M 820 & R 0623 & M 783 a-I \\
\hline R 0144 & M 744 & R 0630 & M 780 \\
\hline R 0152 & M 810 & R 0638 & M 730 \\
\hline R 0154 & missing & R 0645 & M 799 \\
\hline R 0183 & M 749 & R 0646 & M 793 \\
\hline R 0186 & M 745 & R 0647 & M 825 \\
\hline R 0188 & M 822 a, b & R 0649 & M 790 a, b \\
\hline R 0191 & M 743 & R 0666 & M 804 \\
\hline R 0192 & M $811 a, b$ & R 0707 & M 788 \\
\hline R 0255 & M 821 & R 0710 & M 739 \\
\hline R 0256 & M 823 & R 0712 & M $787 \mathrm{a}, \mathrm{b}$ \\
\hline R 0262 & M 815 & R 0714 & M 773 \\
\hline R 0267 & M 776 & R 0751 & M 781 \\
\hline R 0268 & M 778 & R 0762 & M 737 \\
\hline R 0269 & M 753 & R 0850 & M 786 \\
\hline R 0315 & M 777 & R 0853 & M 764 \\
\hline R 0316 & M 750 & R 0881 & M 758 \\
\hline R 0317 & M 751 & R 0936 & M 752 a-e \\
\hline R 0318 & M 736 a-c & R 0987 & M 757 \\
\hline R 0319 & M 779 & R 0989 & M 770 \\
\hline R 0320 & M 782 & R 1003 & M 769 \\
\hline R 0321 & M 789 & R 1019 & M 801 \\
\hline R 0322 & M 759 & R 1021 & M 762 \\
\hline R 0323 & M 765 a-g & R 1029 & M 741 \\
\hline R 0324 & M 748 & R 1030 & M 816 \\
\hline R 0325 & M 760 & R 1032 & M 746 \\
\hline R 0326 & M 771 & R 1033 & M 747 \\
\hline R 0327 & M 798 & R 1034 & M 742 \\
\hline R 0328 & M 797 & R 1035 & M 814 \\
\hline R 0330 & M 795 & R 1044 & M 761 \\
\hline R 0350 & missing & R 1365 & M 808 \\
\hline R 0351 & M 794 & R 1367 & M 763 \\
\hline R 0352 & M 803 & R 1374 & M 792 \\
\hline R 0353 & M 802 & R 1521 & M 813 \\
\hline
\end{tabular}




\section{APPENDIX 2 - Continuation}

IRSNB "Anciens numéros de registre" (historical register numbers) and "Numéros Types et Figurés" (new catalogue numbers). Conversion of new IRSNB collection numbers into old IRSNB register numbers.

\begin{tabular}{|c|c|}
\hline New catalogue numbers & Historical register numbers \\
\hline M $000-$ missing & R 0154 \\
\hline M 000 - missing & R 0350 \\
\hline M 690 & R 0011 \\
\hline M 730 & R 0638 \\
\hline M 736 a-c & R 0318 \\
\hline M 737 & R 0762 \\
\hline M 738 & R 0136 \\
\hline M 739 & R 0710 \\
\hline M 740 & R 0611 \\
\hline M 741 & R 1029 \\
\hline M 742 & R 1034 \\
\hline M 743 & R 0191 \\
\hline M 744 & R 0144 \\
\hline M 745 & R 0186 \\
\hline M 746 & R 1032 \\
\hline M 747 & R 1033 \\
\hline M 748 & R 0324 \\
\hline M 749 & R 0183 \\
\hline M 750 & R 0316 \\
\hline M 751 & $\mathrm{R} 0317$ \\
\hline M 752 a-e & R 0936 \\
\hline M 753 & R 0269 \\
\hline M 754 a-i & R 0025 \\
\hline M 755 a-i & R 0016 \\
\hline M $756 a, b$ & R 0015 \\
\hline M 757 & R 0987 \\
\hline M 758 & R 0881 \\
\hline M 759 & R 0322 \\
\hline M 760 & R 0325 \\
\hline M 761 & R 1044 \\
\hline M 762 & R 1021 \\
\hline M 763 & R 1367 \\
\hline M 764 & R 0853 \\
\hline M 765 a-g & R 0323 \\
\hline M 766 & R 0538 \\
\hline M 767 a-c & R 0522 \\
\hline M 769 & R 1003 \\
\hline M 770 & R 0989 \\
\hline M 771 & R 0326 \\
\hline M 772 & R 0040 \\
\hline M 773 & R 0714 \\
\hline M 774 & R 0367 \\
\hline M $775 a, b$ & R 0368 \\
\hline M 776 & R 0267 \\
\hline M 777 & $R 0315$ \\
\hline M 778 & R 0268 \\
\hline
\end{tabular}

\begin{tabular}{|c|c|}
\hline New catalogue numbers & Historical register numbers \\
\hline M 779 & R 0319 \\
\hline M 780 & R 0630 \\
\hline M 781 & R 0751 \\
\hline M 782 & R 0320 \\
\hline M 783 a-I & R 0623 \\
\hline M 784 & R 0090 \\
\hline M $785 a, b$ & R 0107 \\
\hline M 786 & R 0850 \\
\hline M 787 a, b & R 0712 \\
\hline M 788 & R 0707 \\
\hline M 789 & R 0321 \\
\hline M 790 a, b & R 0649 \\
\hline M $791 \mathrm{a}-\mathrm{v}$ & R 0047 \\
\hline M 792 & R 1374 \\
\hline M 793 & R 0646 \\
\hline M 794 & R 0351 \\
\hline M 795 & R 0330 \\
\hline M $796 a, b$ & R 0022 \\
\hline M 797 & R 0328 \\
\hline M 798 & R 0327 \\
\hline M 799 & R 0645 \\
\hline M 801 & R 1019 \\
\hline M 802 & R 0353 \\
\hline M 803 & R 0352 \\
\hline M 804 & R 0666 \\
\hline M 805 & R 0354 \\
\hline M 806 & R 0521 \\
\hline M 807 & R 0560 \\
\hline M 808 & R 1365 \\
\hline M 809 a-d & R 0363 \\
\hline M 810 & R 0152 \\
\hline M 811 a, b & R 0192 \\
\hline M 812 & R 0533 \\
\hline M 813 & R 1521 \\
\hline M 814 & R 1035 \\
\hline M 815 & R 0262 \\
\hline M 816 & $R 1030$ \\
\hline M 817 & R 0561 \\
\hline M 818 & R 0139 \\
\hline M 819 & R 0140 \\
\hline M 820 & R 0141 \\
\hline M 821 & R 0255 \\
\hline M $822 \mathrm{a}, \mathrm{b}$ & R 0188 \\
\hline M 823 & R 0256 \\
\hline M 824 & R 0562 \\
\hline M 825 & R 0647 \\
\hline
\end{tabular}




\section{APPENDIX 3}

Measurements (in mm) of the cranium of Diunatans luctoretemergo n. gen., n sp., holotype NHG 22279a, b and paratype NHG $22347 a$, b. The numbers 1-30 correspond to the numbers in the Figure 14. Abbreviations: e, estimate; NHG, Natuurhistorische collectie van het Zeeuws Genootschap der Wetenschappen, Middelburg, The Netherlands.

\begin{tabular}{rlcc}
\hline & & NHG 22279 & NHG 22347 \\
\hline 1 & Zygomatic width & e 740 & e 754 \\
2 & Exoccipital width & 485 & e 524 \\
3 & Condylar width & 170 & e 184 \\
4 & Width side to side at anterior process of periotic & 360 & e 370 \\
5 & Width of basicranium at basioccipital crest & 170 & damaged \\
6 & Length: posterior condylus occipitalis-anterior side of nasals & 520 & missing \\
7 & Height of cranium: dorsal side of nasals-ventral side of vomer & 175 & missing \\
8 & Width of squamosal, lateral to the supraoccipital & 105 & 115 \\
9 & Width of vertex at anterior supraoccipital & 170 & missing \\
10 & Width of vertex at posterior nasals & 171 & missing \\
11 & Width of vertex at anterior nasals & 185 & missing \\
12 & Width of anterior nares & 75 & missing \\
13 & Width of premaxilla at vertex & 12 & missing \\
14 & Width of premaxilla at anterior nares & 22 & missing \\
15 & Overlap: parietal-frontal (parallel to axis) & 83 & missing \\
16 & Overlap: parietal-maxilla (parallel to axis) & 53 & missing \\
17 & Length of frontal on vertex (maximum length; parallel to axis) & 20 & missing \\
18 & Length of nasal (parallel to axis) & 95 & missing \\
19 & Length of occipital shield (posterior condyles-anterior vertex) & 405 & missing \\
20 & Height of condylus occipitalis (ventrodorsal) & 110 & 130 \\
21 & Length: anterior occipital shield-posterior premaxilla & 22 & missing \\
22 & Length of pterygoid fossa (parallel to axis) & 200 & 210 \\
23 & Width of pterygoid fossa (perpendicular to axis) & 105 & 105 \\
24 & Width of basioccipital crest (perpendicular to axis) & 65 & damaged \\
25 & Width of posterior process of periotic (perpendicular to axis) & 92 & 102 \\
26 & Greatest length of pars cochlearis (not parallel to axis) & 60 & 48 \\
27 & Greatest width of pars cochlearis (not parallel to axis) & 47 & 39 \\
28 & Length/width ratio promontorium & 1.26 & 1.23 \\
29 & Length of bulla (parallel to axis) & 101 & missing \\
30 & Width of bulla at processus sigmoideus (perpendicular to axis) & 81 & missing \\
31 & Length/width ratio of bulla & 1.24 & missing \\
\hline
\end{tabular}

\section{APPENDIX 4}

List of bivalves and gastropods molluscs collected from the matrix of the type specimen of Diunatans luctoretemergo $\mathrm{n}$. gen., $\mathrm{n}$ sp. Abbreviation: NHG, Natuurhistorische collectie van het Zeeuws Genootschap der Wetenschappen, Middelburg, The Netherlands.

\begin{tabular}{llcc}
\hline Species & Period & Size (mm) & Collection number \\
\hline Calyptrea chinensis (Linnaeus, 1758) & Miocene-recent & 9.7 & NHG-22279-i \\
Ringicula buccinea (Brocchi, 1814) & Miocene (?)-Lower Pliocene & 6 & NHG-22279-g \\
Isocrassina omalii (de la Jonkaire, 1823) & Lower Pliocene & 30 & NHG-22279-f \\
Parvicardium scabrum (Philippi, 1844) & Pliocene-recent & 13 & NHG-22279-j1 \\
Mactra glauca von Born, 1778 & Pliocene-recent & 22 & NHG-22279-b \\
Arctica islandica (Linnaeus, 1767) & Miocene-recent & $>31$ & NHG-22279-k \\
Corbula gibba gibba (Olivi, 1792) & Miocene-recent & 5 & NHG-22279-h \\
Thracia altenai Glibert \& Van de Poel, 1966 1966 & Early-middle Pliocene & 6 & NHG-22279-j2 \\
& & 9.5 & NHG-22279-I \\
\hline
\end{tabular}


APPENDIX 3 - Continuation

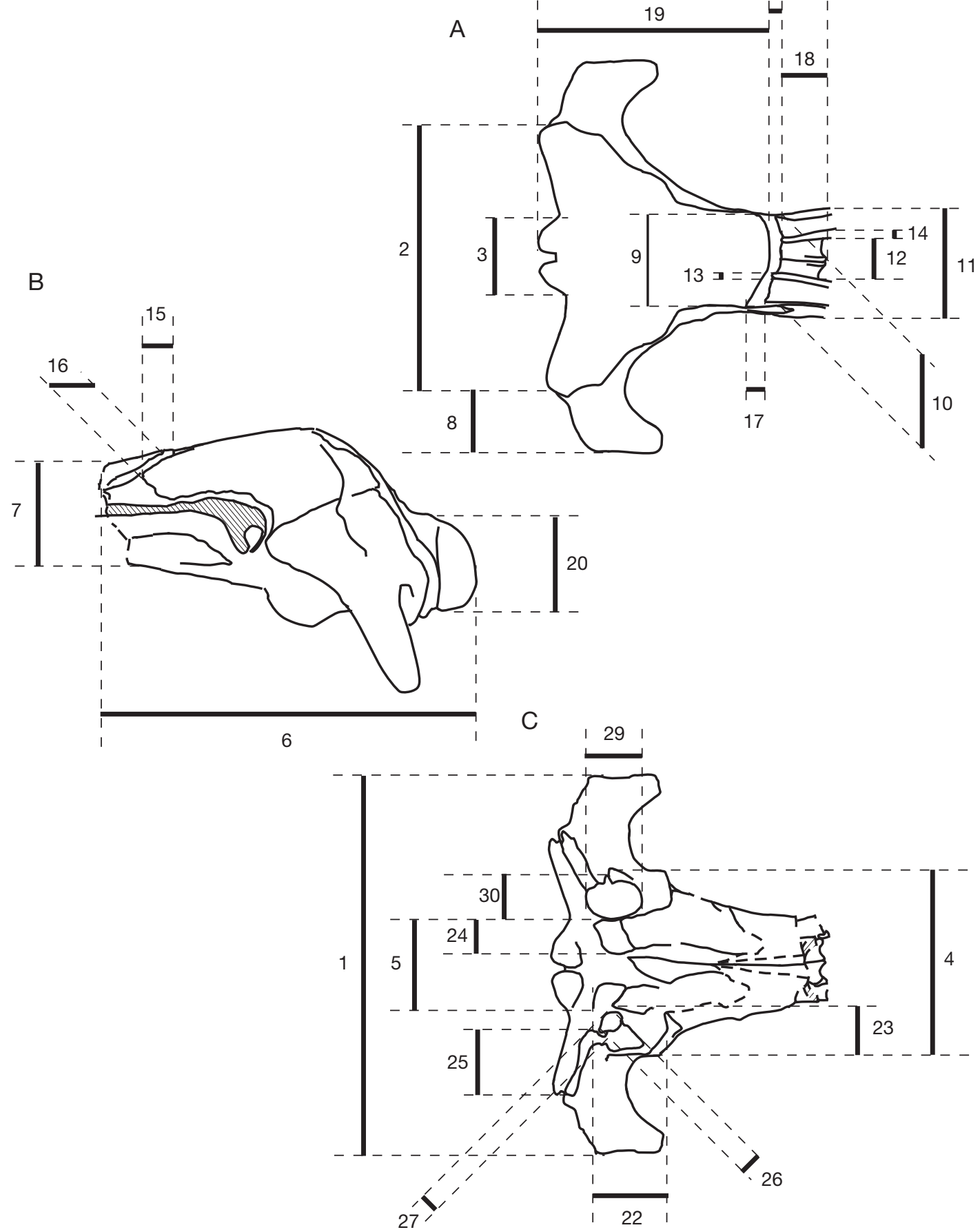

FIG. 14. - Description of measurements of the cranium of Diunatans luctoretemergo n. gen., n. sp.: A, dorsal view; B, left lateral view; C, ventral view. The numbers correpond to and illustrate the measurements in Appendix 3. 